Article

\title{
Divergent Proteomic Responses Offer Insights into Resistant Physiological Responses of a Reef-Foraminifera to Climate Change Scenarios
}

\author{
Marleen Stuhr 1,2,3,*iD, Louise P. Cameron ${ }^{3,4}$, Bernhard Blank-Landeshammer ${ }^{5}$, Claire E. Reymond ${ }^{3}(\mathbb{D}$, \\ Steve S. Doo ${ }^{3}\left(\mathbb{D}\right.$, Hildegard Westphal ${ }^{3,6}$, Albert Sickmann ${ }^{5,7,8}$ and Justin B. Ries ${ }^{3,4}$ \\ check for \\ updates \\ 1 Interuniversity Institute for Marine Sciences, Eilat 8810302, Israel \\ The Mina and Everard Goodman Faculty of Life Sciences, Bar-Ilan University, Ramat Gan 52900, Israel \\ 3 Leibniz Centre for Tropical Marine Research (ZMT), 28359 Bremen, Germany; \\ cameron.lo@northeastern.edu (L.P.C.); claire.reymond@gmail.com (C.E.R.); steve.doo@leibniz-zmt.de (S.S.D.); \\ hildegard.westphal@leibniz-zmt.de (H.W.); j.ries@northeastern.edu (J.B.R.) \\ 4 Department of Marine and Environmental Sciences, Marine Science Center, Northeastern University, \\ Boston, MA 01908, USA \\ 5 Leibniz Institut für Analytische Wissenschaften-ISAS-e.V., 44139 Dortmund, Germany; \\ bernhard.blank@mailbox.org (B.B.-L.); sickmann@isas.de (A.S.) \\ 6 Department of Geosciences, Bremen University, 28359 Bremen, Germany \\ 7 Medizinische Fakultät, Medizinische Proteom-Center (MPC), Ruhr-Universität Bochum, \\ 44801 Bochum, Germany \\ 8 Department of Chemistry, University of Aberdeen, Old Aberdeen, Scotland AB24 3UE, UK \\ * Correspondence: marleen.stuhr@leibniz-zmt.de
}

Citation: Stuhr, M.; Cameron, L.P.; Blank-Landeshammer, B.; Reymond, C.E.; Doo, S.S.; Westphal, H.; Sickmann, A.; Ries, J.B. Divergent Proteomic Responses Offer Insights into Resistant Physiological Responses of a Reef-Foraminifera to Climate Change Scenarios. Oceans 2021, 2, 281-314. https://doi.org/ 10.3390 /oceans 2020017

Academic Editor: Jonathan Y.S. Leung

Received: 31 December 2020

Accepted: 25 March 2021

Published: 1 April 2021

Publisher's Note: MDPI stays neutral with regard to jurisdictional claims in published maps and institutional affiliations.

Copyright: (c) 2021 by the authors. Licensee MDPI, Basel, Switzerland. This article is an open access article distributed under the terms and conditions of the Creative Commons Attribution (CC BY) license (https:// creativecommons.org/licenses/by/ $4.0 /)$.

\begin{abstract}
Reef-dwelling calcifiers face numerous environmental stresses associated with anthropogenic carbon dioxide emissions, including ocean acidification and warming. Photosymbiontbearing calcifiers, such as large benthic foraminifera, are particularly sensitive to climate change. To gain insight into their responses to near-future conditions, Amphistegina lobifera from the Gulf of Aqaba were cultured under three $p \mathrm{CO}_{2}$ conditions $(492,963,3182 \mathrm{ppm})$ crossed with two temperature conditions $\left(28{ }^{\circ} \mathrm{C}, 31^{\circ} \mathrm{C}\right)$ for two months. Differential protein abundances in host and photosymbionts were investigated alongside physiological responses and microenvironmental $\mathrm{pH}$ gradients assessed via proton microsensors. Over 1000 proteins were identified, of which $>15 \%$ varied significantly between treatments. Thermal stress predominantly reduced protein abundances, and holobiont growth. Elevated $p \mathrm{CO}_{2}$ caused only minor proteomic alterations and color changes. Notably, $\mathrm{pH}$ at the test surface decreased with increasing $p \mathrm{CO}_{2}$ under all light/dark and temperature combinations. However, the difference between $\left[\mathrm{H}^{+}\right]$at the test surface and $\left[\mathrm{H}^{+}\right]$in the seawater-a measure of the organism's mitigation of the acidified conditions-increased with light and $p \mathrm{CO}_{2}$. Combined stressors resulted in reduced pore sizes and increased microenvironmental $\mathrm{pH}$ gradients, indicating acclimative mechanisms that support calcite test production and/or preservation under climate change. Substantial proteomic variations at moderate- $p \mathrm{CO}_{2}$ and $31^{\circ} \mathrm{C}$ and putative decreases in test stability at high- $p \mathrm{CO}_{2}$ and $31{ }^{\circ} \mathrm{C}$ indicate cellular modifications and impacts on calcification, in contrast to the LBFs' apparently stable overall physiological performance. Our experiment shows that the effects of climate change can be missed when stressors are assessed in isolation, and that physiological responses should be assessed across organismal levels to make more meaningful inferences about the fate of reef calcifiers.
\end{abstract}

Keywords: Amphistegina lobifera; coral reef; global warming; large benthic foraminifera; LC-MS/MS proteomics; ocean acidification; $\mathrm{pH}$ microsensor; photosymbiotic calcifier; Red Sea; thermal stress 


\section{Introduction}

Anthropogenic carbon dioxide $\left(\mathrm{CO}_{2}\right)$ emissions affect ecosystems worldwide [1]. Marine environments are impacted by both ocean warming $(\mathrm{OW})$ and ocean acidification $(\mathrm{OA})$ that result from rising atmospheric $\mathrm{CO}_{2}$. The associated rise in seawater temperature poses a major threat to coral reef ecosystems [2]. Alongside the altered carbonate chemistry and saturation states [3-5], warming represents a substantial challenge for marine calcifiers to overcome [6] as it leads to the breakdown of the symbiosis between host organisms, like corals and foraminifera, and their photosymbionts. OA has various impacts on biomineralization and skeleton construction [7,8], with photosymbiotic reef organisms, such as scleractinian corals, often showing non-linear and even parabolic responses [9-11]. The responses of photosymbiotic organisms can be difficult to predict due to their differential yet potentially complementary modification of carbonate chemistry within their cytoplasm, but also in their microenvironment, during photosynthesis and calcification [12-14]. Moreover, global stressors are acting in concert, potentially compounding the physiological responses of shallow-water marine calcifiers [15], which adds to the complexity of predicting the fate of coral reef organisms under future global change scenarios.

Large benthic foraminifera (LBF) are protistan eukaryotes that build calcareous shells, known as tests, and host endosymbiotic microalgae. The proliferation of these and other calcifying tropical/subtropical reef organisms, including corals, are augmented by photosynthesizing endosymbiotic microalgae. The energetic advantages of this association arise from the photosynthate-derived carbohydrates that are released by the symbionts to the host [16,17], thus facilitating LBF to be major calcium carbonate producers within reef ecosystems and contribute significantly to the global carbon cycle [18,19]. The taxonomic family Amphisteginidae has occurred in the fossil record for the past 50-60 million years, and is one of the most scientifically recognized and widespread modern families of LBF [20]. Amphistegina spp. appear more resilient to thermal stress than many other LBF [21-23], which could be an adaptation from ancestors of the Paleogene, when atmospheric $\mathrm{CO}_{2}$ fluctuated substantially and was generally 2- to 3-fold higher than Neogene levels [24]. During the middle Eocene, Amphistegina spp. and other hyaline LBF were extremely diverse and dominant in shallow tropical marine carbonate environments [25], when atmospheric $\mathrm{CO}_{2}$ was similar to or higher than today [26]. Recently, 18S SSU rDNA markers have shown how rich diversification and broad geographic distribution have contributed to the withstanding of Amphistegina spp. to extinction events throughout evolutionary history [27], however, it remains unclear which adaptive traits exactly facilitated these photosymbiotic calcifiers to thrive throughout such variable environmental conditions and maintain their long-lasting evolutionary success. In modern settings, Amphistegina spp. are prevalent throughout the tropical/subtropical coastal environments [28,29], and are known to occur in such high densities that they can locally represent $>1500 \mathrm{~g}$ per $\mathrm{m}^{2} \mathrm{CaCO}_{3}$ of marine sediments [30], contributing substantially to sand production and beach nourishment.

Generally, LBF seem to be more tolerant of and adaptive to ocean warming and acidification compared to corals, but the underlying mechanisms of variations in sensitivity to global change are not fully understood [31]. Ocean warming and high light intensities are known to cause LBF bleaching [32,33]. The reductions in photosymbiont densities or pigmentations are associated with impaired host performance, including reduced photosynthesis and respiration, motility, growth and antioxidant production (e.g., [23,34,35]). Such effects are often accompanied by increased proportions of malformed or broken tests, infections, and reproductive dysfunction [36]. Yet, there are LBFs with remarkably high thermal thresholds, such as A. lobifera from the Gulf of Aqaba [22] — similar to many other marine species from the northern Red Sea $[37,38]$. The results of laboratory and field-based experiments on the effects of OA, however, range from predicting extinction of LBF by 2100 [39], and other negative impacts like test dissolution, reduced growth, lower chl $a$ concentration and photosynthesis (790-1100 $\mu$ atm [21,40-44]), to no significant effects on photosynthesis, chl $a$ and net production/growth (up to $1925 \mu \mathrm{atm}[41,45]$ ) or positive 
effects such as increased symbiont performance or higher growth rates (580-770 $\mu$ atm or $1169-1662 \mu$ atm $[40,41,44-47])$.

The effects of the combination of these stressors on LBF physiology has received little study thus far $[21,41,48]$. Each compartment of the holobiont (photosymbiont or host) could react depending on the environmental conditions, functional group and life cycle of the organisms, and the test mineralogy [19], thus making the interactive effects of future global change on LBF hard to predict. Mass spectrometry-based bottom-up proteomics was recently proven to be a powerful tool for detecting cellular responses among Amphistegina spp. [49], especially as this approach allows quantification of changes in algal symbiont and/or the host foraminifera simultaneously. Application of proteomics approaches may thus reveal the bio-functional mechanisms involved in maintaining homeostasis and symbiosis under rapidly changing environmental conditions.

To test the tolerance of a globally distributed shallow-water LBF to the independent and combined effects of OA and OW, a crossed-factor laboratory experiment was set up. Amphistegina lobifera from the northern Red Sea were cultured under elevated temperature ( $\mathrm{T}$, control $=28^{\circ} \mathrm{C}$ and high $=31^{\circ} \mathrm{C}$ ) and three $p \mathrm{CO}_{2}$ scenarios (ambient $/$ control $=492 \mathrm{ppm}$, year $2100 /$ moderate $=963 \mathrm{ppm}$, and year 2500 $/$ high $=3182 \mathrm{ppm} \mathrm{[1])} \mathrm{for} \mathrm{two} \mathrm{months.} \mathrm{Ef-}$ fects on its physiological performance, diffusive boundary layer (DBL) $\mathrm{pH}$, and host and photosymbiont proteomes were investigated by measuring proton concentrations on the test surface and in the surrounding seawater during dark and light (via microsensors), holobiont mortality (as frequency of empty tests), growth (as changes in cross-sectional area area), and color (on the $L^{*} a^{*} b^{*}$ color scale as proxy for photophysiological condition), chlorophyll $a$ concentration (as proxy for photosymbiont biomass), test pore size (on newest chamber), as well as changes in relative abundance of proteins associated with host foraminifera and/or their photosymbiotic diatoms (via liquid chromatography-tandem mass spectrometry [LC-MS/MS] proteomics). This combined approach focuses on detecting molecular alterations at the proteomic level, representing mechanisms that contribute to holobiont functioning, as well as the downstream functional performance development of LBF to future climate change. Elucidating the cellular mechanisms responsible for acclimatization and resilience of photosymbiotic calcifiers will ultimately contribute to our understanding of how coral reefs evolve, aiding in their conservation and restoration.

\section{Materials and Methods}

Amphistegina lobifera harbor diatoms as endosymbionts [22,50-52]. Adult specimens of A. lobifera reach sizes of $>1 \mathrm{~mm}$ in diameter [53,54], the spherical perforate test is built of intermediate- $\mathrm{Mg}$ calcite, $\sim 4-6 \mathrm{~mol} \% \mathrm{MgCO}_{3}$ [55]. At depths $<10 \mathrm{~m} \mathrm{~A}$. lobifera is the shallowest dwelling foraminifera of the genus and is commonly found attached to coral rubble in the upper reef slope, reef flat, and back reef zones [56,57]. This genus has a broad geographic distribution and specimens from the Red Sea, along with populations from the western Indian Ocean and the Mediterranean Sea, belong to lineage Ia [27].

\subsection{Sample Collection}

Collection procedures followed established protocols [58]. Initially, coral rubble was collected from the narrow and patchy fringing reef $\left(29^{\circ} 30.619 \mathrm{~N}, 34^{\circ} 55.247 \mathrm{E}\right)$ in the northernmost extension of the Red Sea, the Gulf of Aqaba (GoA) [28,59]. Samples were obtained by snorkeling in 2-4 $\mathrm{m}$ deep water in front of the Inter-University Institute for Marine Sciences (IUI) in Eilat, Israel, in March 2016. LBF specimens were removed from the rubble and transported to the Leibniz Centre for Tropical Marine Research (ZMT), Bremen, in thermally insulated containers for $<12 \mathrm{~h}$. Temperature loggers (Onset $\mathrm{HOBO}^{\circledR}$, Bourne, MA, USA) were placed in the containers at a temperature of $23.3^{\circ} \mathrm{C}$ (standard deviation $(\mathrm{SD})=1.3)$, which is within the normal daily temperature range for the species. Upon arrival at the marine experimental facility (MAREE) at ZMT, the samples were cultured under low-light intensities of $15-20 \mu \mathrm{mol}$ photons $\mathrm{m}^{-1} \mathrm{~s}^{-1}$ (LICOR LI-250) to recover from transport. Since the water temperature during collection at springtime $\left(\sim 23^{\circ} \mathrm{C}\right)$ was 
relatively low compared to the target-temperatures of the experiment $\left(28^{\circ} \mathrm{C}, 31^{\circ} \mathrm{C}\right)$, the specimens were slowly acclimated to the experimental target temperatures by exposing them to a temperature of $24^{\circ} \mathrm{C}-25.5^{\circ} \mathrm{C}$ during the first week. After this, the foraminifera were distributed amongst the experimental aquaria initially maintained at $26{ }^{\circ} \mathrm{C}$, after which the temperature was ramped up by $1{ }^{\circ} \mathrm{C}$ per day until the final temperature levels of $28^{\circ} \mathrm{C}$ or $31^{\circ} \mathrm{C}$ were reached. Although mean annual temperatures at the collection site in the GoA rarely reach $28^{\circ} \mathrm{C}$, that temperature was selected as the control because a prior study showed that growth and photosynthetic performance of $A$. lobifera from the GoA were not impacted by a three-week exposure to temperatures of up to $30^{\circ} \mathrm{C}$ [22]. As their thermal threshold appears to be slightly above this value, and because global sea-surface temperatures are expected to rise by an average of $3{ }^{\circ} \mathrm{C}\left(\mathrm{RCP} 8.5\right.$ [1]), $31^{\circ} \mathrm{C}$ was used as the high-temperature treatment. These experimental temperatures also correspond to the summertime thermal range at the sampling location (Fine et al., 2013, [37]). Temperatures were maintained at $28^{\circ} \mathrm{C}\left(\mathrm{SD} \mathrm{0.2)}\right.$ and $31^{\circ} \mathrm{C}$ (SD 0.3) using 125-watt aquarium heaters (EHEIM, Deizisau, Germany).

\subsection{Experimental Design}

A crossed-factor laboratory experiment with six treatments, two T levels (control $=28^{\circ} \mathrm{C}$, high $=31{ }^{\circ} \mathrm{C}$ ), and three $p \mathrm{CO}_{2}$ scenarios (ambient $/$ control $=492 \mathrm{ppm}$; year $2100 /$ moderate $=963 \mathrm{ppm}$; year 2500/high $=3182 \mathrm{ppm}$ [1]) were replicated four times ( $\mathrm{n}=24$ tanks in total), was set up. The culturing array consisted of six 284-L seawater reservoirs, which were comprised of two seawater basins and four 10-L replicate tanks. Specimens were reared for eight weeks in each of the 10-L aquaria ( $\geq 18$ specimens per replicate tank, $>432$ specimens in total). This study was conducted in parallel with scleractinian coral specimens in the same experimental array. Corals held in the same experimental array $[15,60]$ were fed live Artemia sp. hatched from $\sim 40 \mathrm{mg}$ of eggs within $24 \mathrm{~h}$ every second day, which also supplied sufficient organic matter and nutrients to the foraminifera maintained in the same tanks, especially since $A$. lobifera has previously been shown to depend very little on heterotrophic feeding [61,62]. Natural oligotrophic seawater collected from Svalbard, Norway, was used.

Foraminifera were housed in 48 custom-made transparent plastic containers cut open on both sides (approximately $1 \times 2 \times 5 \mathrm{~cm}$ ) and covered with 400- $\mu \mathrm{m}$ nylon mesh fixed by coral glue (EcoTech Marine, Bethlehem, PA, USA). This arrangement allowed water to circulate through the submerged containers. Two of these containers were placed in each of the 24 10-L replicate tanks (4 replicate tanks per treatment). One of the two containers held eight specimens that served for assessing growth and mortality. The other container held at least ten specimens, one to two of which underwent $\mathrm{pH}$ microelectrode measurements, chl $a$ extractions, and scanning electron microscopy (SEM) imaging, while the remaining eight specimens were used for proteomic analysis.

The tanks were illuminated for $12 \mathrm{~h}$ per day with compact fluorescent lights (ultraactinic and white; $96 \mathrm{~W}, 1000 \mathrm{~K}$ ) combined with standard white fluorescent lights (32 W, T8, $6500 \mathrm{~K}$ ), with a maximum photosynthetically active radiation (PAR) of $\sim 250 \mu \mathrm{mol}$ photons $\mathrm{m}^{-2} \mathrm{~s}^{-1}$ to meet the light intensity needed for the zooxanthellate corals cultured in the same experiment. To account for the needs of $A$. lobifera, the irradiance was reduced by a factor of ten (to $25-35 \mu \mathrm{mol}$ photons $\mathrm{m}^{-1} \mathrm{~s}^{-1}$ ) by shading with the black nylon mesh. Light measurements were conducted using a quantum light meter (LI-COR LI-250A) with a submersible spherical micro-quantum sensor (Walz, Effeltrich, Germany).

The seawater in all of the experimental tanks was equilibrated with mixed gases formulated at three $p \mathrm{CO}_{2}$ levels. The control- $p \mathrm{CO}_{2}$ treatment was set at $492 \mathrm{ppm}$ (SD 80 ) to emulate control (C) present-day conditions, the moderate- $p \mathrm{CO}_{2}$ treatment (M) was set at $963 \mathrm{ppm}$ (SD 134) to emulate predicted year-2100 conditions, and the high- $p \mathrm{CO}_{2}$ treatment $(\mathrm{H})$ was set at $3182 \mathrm{ppm}(\mathrm{SD} 817)$ to emulate predicted year-2500 conditions [1,5]. To achieve the target $p \mathrm{CO}_{2}$ conditions, $\mathrm{CO}_{2}$-free air and pure $\mathrm{CO}_{2}$ gas were mixed with 
solenoid-valve-controlled mass flow controllers and bubbled via flexible microporous air stones into the two large seawater reservoirs of each experimental treatment group.

Seawater was continuously pumped from the lower large reservoir to the four replicate tanks contained within the upper large reservoir of each treatment group using a 30-watt aquarium pump (output $=2700 \mathrm{~L} \mathrm{~h}^{-1}$, Aqua Medic Eco Runner 2700). Seawater was distributed to each replicate tank via two horizontal pipes with holes drilled along their long-axes and placed at both ends of the tank, one at the top of the tank and one at the bottom, so that the corals and foraminifera specimens received laminar, circulating flow. Seawater overflowed the replicate tanks into the large upper reservoir then into the lower reservoir where it was filtered by activated charcoal (Deltec brand protein skimmer) and a filter medium pad. The seawater was continuously recirculated from the lower reservoir to the replicate tanks in the upper reservoirs using an aquarium pump. Seawater from the reserve tank was added to each experimental treatment group at a rate of $0.6 \mathrm{~L} \mathrm{~h}^{-1}$, which allows seawater to mix at near-equilibrium within each tank, thereby maintaining target carbonate chemistry of the experimental seawater's dissolved constituents via calcification and photosynthesis (e.g., $\mathrm{Ca}^{2+}$, alkalinity, nutrients). Each treatment group was covered with a transparent Plexiglas lid to prevent in-/outgassing from the seawater and to minimize evaporation.

Following the methods of Guillermic et al. [15], salinity, $\mathrm{pH}$, and temperature were measured three times per week in all of the replicate tanks using a combination probe kit (WTW Multi 3430 Set K). The $\mathrm{pH}$ and salinity sensors (Thermo Orion ${ }^{\mathrm{TM}}$ ) were calibrated at the appropriate tank temperature $\left(28^{\circ} \mathrm{C}\right.$ or $\left.31^{\circ} \mathrm{C}\right)$ before each measurement using NIST-traceable pH 4 and 7 NBS buffers and Certified Seawater Reference Material (Dickson standard batch \#154) of salinity 33.347, respectively. Total alkalinity (TA) and dissolved inorganic carbon (DIC) samples were collected once per week at midday, thereby minimizing disparities in DIC due to diurnal variations in the photosynthetic activity and respiration of the tank inhabitants. DIC samples were collected in sealed $25 \mathrm{~mL}$ borosilicate glass vials and TA samples were collected in $50 \mathrm{~mL}$ centrifuge tubes that were twice flushed with seawater prior to use. Subsequently, DIC and TA samples were preserved with $10 \mu \mathrm{m}$ and $20 \mu \mathrm{m}$, respectively, of saturated mercuric chloride solution and refrigerated until analysis. TA was measured by open-cell potentiometric Gran titration (accuracy $\pm 20 \mu \mathrm{mol} \mathrm{kg}^{-1}$ ) and DIC was measured with a Shimadzu DOC analyzer converted for DIC analysis (accuracy $\pm 10 \mu \mathrm{mol} \mathrm{kg}^{-1}$ ). Every seventh sample, the TA and DIC instruments were calibrated with Certified Seawater Reference Material (Dickson Batch \#154). Concentration of carbonate ions, bicarbonate ions, aqueous $\mathrm{CO}_{2}$, aragonite $\left(\Omega_{\mathrm{A}}\right)$, and calcite saturation states $\left(\Omega_{\mathrm{C}}\right)$ were calculated from measured TA, DIC, salinity, and temperature with CO2SYS software [63] using Roy et al. [64] values for the $K_{1}$ and $K_{2}$ carbonic acid constants, the Mucci [65] value for the stoichiometric aragonite and calcite solubility products and with an atmospheric pressure of $1.015 \mathrm{~atm}$.

\subsection{Physiological Assessment}

\subsubsection{Microelectrode Measurements}

Microsensors are commonly used to characterize the DBL that exists between the surface of an organism and the surrounding seawater (e.g., [7,12,66,67]). Among foraminifera, oxygen and $\mathrm{pH}$ gradients of the DBL reflect photosynthesis, respiration, and biomineralization activity [12-14]. To investigate the DBL of LBF, liquid ion exchange (LIX) $\mathrm{pH}$ microelectrodes were fabricated in the de Beer laboratory (Max Planck Institute for Marine Microbiology, Bremen). Microsensors were produced following de Beer et al. [68], but were filled with hydrogen ionophore II cocktails A and B (Sigma-Aldrich, Darmstadt, Germany), with cocktail B having an epoxy added to it to prevent leakage of the ionophore out of the sensor. Microelectrode measurements were performed in two reservoirs of seawater, sourced from the corresponding experimental treatment tanks, located adjacent to the experimental tanks and the microelectrode system. These reservoirs were bubbled with the corresponding treatment gases and maintained at the corresponding treatment tempera- 
ture using 125-watt aquarium heaters (EHEIM, 2015), mimicking the respective treatment conditions in the experimental aquaria. The seawater was circulated between the two reservoirs through two $5.4 \mathrm{~L}$ flow-through chambers $(30 \times 12 \times 15 \mathrm{~cm})$. All pH microelectrode measurements were performed within these smaller flow-through chambers, with gentle water movement maintained with a small powerhead (12 V Tarwig). Following the methods of Glas et al. [12], single specimens were carefully removed from the experimental culturing setup and placed on the bottom of aquaria. LIX membrane microelectrodes (8-20 $\mu \mathrm{m}$ tip diameter, $\leq 20 \mathrm{~s}$ response time) connected to a high-impedance $\mathrm{mV}$ meter were mounted on a motorized micromanipulator (Micos VT-80). Prior to measurements, the microelectrodes were prepared and calibrated in $\mathrm{pH}$ buffer solutions (Mettler Toledo, $\mathrm{pH}_{\mathrm{NBS}} 7.0$ and 9.21) at treatment temperature, following de Beer et al. [68]. Microelectrode tips were positioned on the LBF test surface. Exact positioning of the specimen and the microsensor tip was achieved using a Stemi SV6 binocular (Zeiss, Oberkochen, Germany).

To determine the effects of photosynthesis and respiration on the $\mathrm{pH}$ microenvironment under the different $p \mathrm{CO}_{2}$ and temperature treatments, the gradient in $\mathrm{pH}$ away from the test surface was measured in three specimens per treatment. The foraminifera were allowed to acclimate to the conditions and recover from handling for five min before initiating $\mathrm{pH}$ measurements. Measurements were first conducted under light until a stable signal was reached, after which the light was turned off. When $\mathrm{pH}$ at the test surface reached a constant level, the light was turned on again and measurement was continued until a stable measurement was reached. This was followed by moving the microelectrode along a 1000- $\mu \mathrm{m}$ vertical profile away from the LBF test surface. A step size of $1 \mu \mathrm{m}$ was used for the first $100 \mu \mathrm{m}$ in order to generate high-spatial-resolution $\mathrm{pH}$ profiles within the DBL at the surface of the test. After this, step size was increased to $20 \mu \mathrm{m}$ in order to characterize $\mathrm{pH}$ of the seawater adjacent to the DBL. Between measurements, a fine brush was gently applied to the LBF to prevent it from articulating and moving away from the sensor. The difference in $\left[\mathrm{H}^{+}\right]$between the DBL (immediately adjacent to test surface) and the seawater (' $\left.\Delta\left[\mathrm{H}^{+}\right]^{\prime}\right)$ was calculated as an indicator of the specimen's mitigation of the acidified conditions.

\subsubsection{Holobiont Mortality and Growth}

At the end of the 8-week experiment, the proportions of live-to-dead specimens in each treatment were recorded. Empty tests, determined by lack of cytoplasmic color and reticulopodial activity [69], indicate either stress-related death, natural death (old age), or reproduction in which the host's cytoplasm undergoes either asexual or sexual, leading to the release of hundreds of juvenile cells into the environment. Based on test size homogeneity, it is assumed all specimens used were from the same cohort. Additionally, there was no evidence of reproduction throughout the experimental period (i.e., no juvenile cells). Therefore, the occurrence of empty tests is assumed most likely to be due to a response to stress resulting in mortality. Mortality rate was calculated as a percentage of all specimens $(n=195)$ from each treatment.

A subset of LBF from each treatment $(n=4$ replicates per treatment) was photographed with a digital light microscope (VHX-5000, Keyence, Neu-Isenburg, Germany) using fixed settings immediately before and after the experiment (as described in Stuhr et al. [23]). The surface areas of all specimens were determined with the image analysis software Fiji [70]. Growth was calculated as the average daily increase in cross-sectional surface area of all specimens from each sample over the eight-week experimental period following ter Kuile and Erez [54]. 


\subsubsection{Color and Chlorophyll $a$}

Holobiont color, as a proxy for photophysiological condition, was determined using the International Commission on Illumination (CIE) $L^{*} a^{*} b^{*}$ color space values of each specimen following Hosono et al. (2012) [71]. In each image, holobiont color and background color were transformed into CIE $L^{*} a^{*} b^{*}$ color space by using the color space converter in Fiji [72], as described in Stuhr et al. [23]. The resulting color values represent the three coordinates within the CIE color space: $L^{*}$ indicates whiteness (brightness) of the color $(0=$ black, $100=$ white $)$ and was shown to correlate to photosynthetic performance as measured via oxygen production rate [71], while $a^{*}$ indicates the position between green (negative values) and magenta (positive values), and $b^{*}$ indicates the position between blue (negative values) and yellow (positive values), serving as indicators for photopigment content. A total of 175 specimens (i.e., those that were alive at the end of the experiment) were used for color measurements.

Chl $a$ concentration was analyzed as a proxy of photosymbiont biomass, adapted from established protocols [32]. Single specimens from three randomly chosen tanks from each treatment, which were also used for microelectrode measurements $(\mathrm{n}=3$ per treatment), were each placed into $320 \mu \mathrm{L}$ of $90 \%$ ethanol to extract pigment, heated to $78{ }^{\circ} \mathrm{C}$ for $5 \mathrm{~min}$, vortexed, and extracted in the dark for $24 \mathrm{~h}$ at $4{ }^{\circ} \mathrm{C}$. Then $300 \mu \mathrm{L}$ of the extraction liquid was measured at absorbances of 630,663, and $750 \mathrm{~nm}$ using a microplate reader (Tecan infinite M200 PRO). After extraction, specimens were dried at $40^{\circ} \mathrm{C}$ for $24 \mathrm{~h}$ and weighed with an analytical balance (Mettler Toledo MX5). Chl $a$ concentrations were calculated following the method of Jeffrey and Humphrey (1975) and normalized to dried test weight [23]. The same procedure was repeated with the remaining specimens $(n=1-4$ per replicate tank/7-10 per treatment) to ensure that the single specimens selected for microelectrode measurements represent the average photosymbiont condition of their respective treatment. The results of prior total chl $a$ contents were added to the respective replicates of these measurements and normalized by their collective dry weight to calculate average chl $a$ concentrations.

\subsubsection{Test Surface, Pore Size and Breakage}

Images of all remaining LBF 'tests' were made by scanning electron microscopy (SEM) to detect dissolution or other alteration of the test surface. The dried samples were mounted on conductive carbon discs attached to specimen stubs and sputter-coated with gold for $35 \mathrm{sec}$ under vacuum. Images of the surface morphology of the mounted specimens were made by secondary electron (SE) microscopy (Tescan VEGA3 XMU), initially at the highest magnification that maintained the entire test in the SEM's field of view, and then at $\sim 2250$-fold magnification. As Amphistegina add a new layer of calcite to their entire test surface during chamber addition (growth), these high magnification images revealed the newest growth of each specimen. Dissolution of each specimen's test surface was assessed visually by comparison with tests formed under the control condition and also by comparison with images of LBF reference samples that were cultured under control conditions. Representative sets of images were assembled for each treatment. Changes in test microstructure were quantitatively assessed by comparing average pore sizes determined in SE images $(\mathrm{n}=72)$ using the function 'Analyze particles' in ImageJ (Version $1.52 \mathrm{f}$; method modified from [73]). The occurrence of partial test breakage visible in SE images, possibly induced during handling, was counted and its percentage in each treatment was calculated.

\subsubsection{Statistics}

Permutational multivariate analyses of variance (PERMANOVA) were conducted on all $\Delta\left[\mathrm{H}^{+}\right]$data, using PAST 4.04. Two-way analysis was used for the fixed effects of $p \mathrm{CO}_{2}$ and $\mathrm{T}$, and a one-way analysis for the fixed effect of light (vs. dark). This was followed by pairwise comparison of $\Delta\left[\mathrm{H}^{+}\right]$data amongst treatments, with $p$-values adjusted for multiple testing following Benjamini and Hochberg [74] at a false-discovery-rate (FDR) q- 
threshold of 0.1. For statistical analyses of physiological parameters, residual and normality plots indicated that assumptions of equal group variance and normality were not violated for chl $a$ concentrations, $L^{*} a^{*} b^{*}$ values, growth rates, or pore sizes, and the Shapiro-Wilk test was used to confirm normal distribution of these data. Changes in these parameters under the respective fixed factors $\mathrm{T}$ and $p \mathrm{CO}_{2}$, or their interaction, were analyzed using linear models for two-factorial analysis of variance (ANOVA). In cases where the linear model indicated significant effects of either of the factors, or a significant interaction between the factors, a posthoc Tukeys' Honest Significant Difference (HSD) test was conducted. For the binary mortality (dead) and breakage data, a nominal logistic model was used with the fixed factors $\mathrm{T}$ and $p \mathrm{CO}_{2}$ or their interaction. All analyses of physiological parameters were conducted in JMP Pro 14.3.0.

\subsection{Identification of Photosymbionts}

LBF are known to harbor a wide range of microalgae. To identify the dominant photosymbiont species in the A. lobifera population from Eilat, a 442-base pairs (bp) fragment of the $3^{\prime}$ end of the $18 \mathrm{~S}$ rDNA was extracted from six specimens, amplified, and sequenced as described in Stuhr et al. [35]. The resulting diatom sequences were deposited at European Nucleotide Archive (ENA) under the study accession number PRJEB33832. Sanger sequences were trimmed and assembled using Geneious 8.1.9. All resulting consensus sequences were identified via BLASTn [75] searches using the default settings for highly similar sequences (megablast) against the NCBI database (accessed December 2018) and several representative sequences (with an e-value below $1 \times 10^{-166}$ ) were manually selected from the results. These sequences were complemented with foraminifera symbiont sequences from [22,35], and other closely related algae formerly reported as photosymbionts in LBF (e.g., in Lee et al. [50]). The collected sequences were aligned using MAFFT v7.310 [76] with the default options and trimmed to equal length at the $3^{\prime}$ and $5^{\prime}$ prime end in BioEdit [77]. Subsequently, identical sequences were removed using Alter [78] and the collapse haplotypes command. The final 407-bp alignment was used to calculate a Maximum Likelihood phylogenetic tree based on the GTR model with gamma distribution and 1000 bootstrap replicates in Mega 6.06 [79]. The final tree is shown with a 50\% bootstrap cut-off (Figure S1).

\subsection{Proteomics}

\subsubsection{Label-Free Peptide Quantification and Protein Identification}

To gain insight into the underlying cellular responses of the photosymbionts and the host foraminifera, a label-free quantitative proteomics approach based on liquid chromatography coupled to tandem mass-spectrometry was applied, as described in Stuhr et al. [49] and provided in Appendix A. At the end of the experiment, eight or nine pooled specimens from three replicate tanks for each treatment (i.e., $>144$ specimens in total) were frozen at $-80^{\circ} \mathrm{C}$ and used for the proteomics analysis. As three out of the initial four biological replicate samples from the control treatment (control $p \mathrm{CO}_{2}$ and $28^{\circ} \mathrm{C}={ }^{\prime} \mathrm{C} 28^{\prime}$ ) were damaged during sample preparation due to defective laboratory equipment, this treatment had to be removed from further statistical analysis. However, technical replicates of the remaining C28 sample, as well as biological replicates from samples that were collected before the temperature ramping of the experiment $(\mathrm{t} 0)$, were measured. These data are provided along with all final treatment data in the ProteomeXchange Consortium via the PRIDE partner repository [80] (dataset identifier PXD009890).

A homology-based search approach allowed peptide sequences to be assigned to either the host or photosymbiont component and identified at the protein level. An updated and enlarged reference dataset for foraminifera, containing the recently published genome sequences of the calcareous benthic foraminifera Globobulimina [81] was used, combined with the publicly available genome data of three diatom species used previously [49]. Clusters of homologous protein sequences were generated from amino acid sequences of all proteins identified in the database search with a sequence identity cut-off of 0.7 . Normalized 
abundance values of the peptides were used to calculate protein cluster abundances. Subsequently, protein descriptions and gene ontology (GO) annotation were obtained via eggNOG-mapper v2 $[82,83]$ using default settings (minimum hit e-value $=0.001$, minimum hit bit-score $=60$, minimum $\%$ of query coverage $=20$ ).

\subsubsection{Differential Protein Abundance and Functional Annotations}

To identify proteins with significantly different abundances between the treatments, multivariate analyses with post hoc identifications were conducted in R 4.0.0. [84], adapting procedures of proteomics studies on anemones [85,86]. To aid in parametric model-fitting, data were log-transformed, and Bray-Curtis dissimilarities were calculated for each pairwise sample comparison to identify the differentially abundant protein-clusters. Analysis of variance by permutation of dissimilarities was conducted using the "adonis" function in the R package "vegan" version 2.5-6 [87]. First, a PERMANOVA, with fixed effects of $p \mathrm{CO}_{2}, \mathrm{~T}$, and their interaction, was conducted on log-transformed normalized abundance values of all proteins, only host-associated proteins, and only photosymbiont-associated proteins. This was followed by pairwise comparisons for significant differences using the "pairwise.perm.manova" function in the R package "RVAideMemoire" [88], with $p$-values adjusted for multiple testing at a FDR of 0.05 [74]. All PERMANOVAs used 9999 permutations. Then, a generalized linear model (GLM) with fixed effect treatments was fitted and compared against a null model (intercept only) using an analysis of deviance $\chi^{2}$ test with $\alpha=0.05$. Differentially abundant proteins (DAPs) were identified with the FDR procedure [74] at a $q$-threshold of 0.05 , correcting for multiple testing. The corresponding $\log _{2}$ fold-changes $\left(\log _{2} \mathrm{FC}\right)$ were derived from average normalized abundance values between treatments.

Further descriptions of DAPs were extracted via OmicsBox 1.3.11 (BioBam Bioinformatics, 2019) by searching via the blast program blastp-fast against all organisms deposited in the public NCBI non-redundant protein sequence database on 9 July 2020 (e-value-hitfilter: 0.001, annotation cut-off: 55, HSP length cut-off: 33, number of hits: 20). Any proteins without a match were designated as hypothetical proteins. For proteins without description in the non-redundant NCBI database, those given by the Swiss-Prot database or eggNOG annotations were used, if available. DAPs were grouped by major functional categories inferred from $\mathrm{GO}$ term annotations describing molecular functions, biological processes, and cellular components, though it should be noted that most of them can function in multiple ways and are not restricted to these categories.

A Fisher's Exact test was conducted to determine whether DAP frequencies differed between host and photosymbionts, and multivariate analyses of log-transformed abundance values of DAPs in JMP Pro 14.3.0. Hierarchical cluster analyses of proteins and samples or treatments, using average distance linkage, as well as principal component analysis (PCA) on row-wise correlations, were performed. Further PCAs were run on total normalized abundance values of each functional category of host- or photosymbiont-associated DAPs. To further focus on those most 'regulated' proteins that varied significantly in abundance between treatments and also showed pronounced fold-changes, only DAPs with $\log _{2} \mathrm{FC} \geq|1|$ between those treatments with Tukeys' $p \leq 0.05$ were extracted and highlighted.

\section{Results}

\subsection{Physicochemical Parameters of Seawater Treatments}

A summary of the measured aquarium seawater parameters T, DIC, TA, calculated seawater $\mathrm{pH}$ on seawater-scale $\left(\mathrm{pH}_{\mathrm{SW}}\right)$, calcite $\left(\Omega_{\mathrm{C}}\right)$ and aragonite saturation states $\left(\Omega_{\mathrm{A}}\right)$ of the treatment seawater, and $p \mathrm{CO}_{2}$ of gas in equilibrium with seawater are provided in Table 1. Salinity and carbonate ion concentrations are found in the supplementary material (Table S1). In all treatments, temperature was maintained at either $28 \pm 0.2{ }^{\circ} \mathrm{C}$ ( \pm indicates SD) or $30.9 \pm 0.3{ }^{\circ} \mathrm{C}$, salinity stayed at $35.6 \pm 0.6$, and seawater remained supersaturated with respect to aragonite $\left(\Omega_{\mathrm{A}}>1\right)$ and calcite $\left(\Omega_{\mathrm{C}}>1\right)$. Calculated $\mathrm{pH}$ SW 
of the experimental treatments was $8.16 \pm 0.11,7.97 \pm 0.07$, and $7.50 \pm 0.11$ in the control (491 ppm), moderate (963 ppm), and high (3192 ppm) $p \mathrm{CO}_{2}$ treatments, respectively.

Table 1. Mean physical and chemical conditions $\pm \mathrm{SD}$ in the different treatments of elevated $p \mathrm{CO}_{2}(\mathrm{C}=492 \mathrm{ppm}$, $\mathrm{M}=963 \mathrm{ppm}, \mathrm{H}=3182 \mathrm{ppm}$ ) crossed with $28^{\circ} \mathrm{C}$ and $31^{\circ} \mathrm{C}$. Temperature $=\mathrm{T}$, dissolved organic carbon $=\mathrm{DIC}$, total alkalinity $=\mathrm{TA}, \mathrm{pH}$ on seawater scale $=\mathrm{pH}_{\mathrm{SW}}, p \mathrm{CO}_{2}$ of gas in equilibrium with seawater $=p \mathrm{CO}_{2}$, calcite saturation state $=$ $\Omega_{\mathrm{C}}$, and aragonite saturation state $=\Omega_{\mathrm{A}}$. Additional data on water conditions are provided in Table S1.

\begin{tabular}{cccccccc}
\hline Treatment & $\mathbf{T}\left({ }^{\circ} \mathbf{C}\right)$ & DIC $(\mu \mathbf{M})$ & TA $(\mu \mathbf{M})$ & pH & $p \mathbf{C O}_{\mathbf{2}}(\mathbf{p p m})$ & $\boldsymbol{\Omega}_{\mathbf{C}}$ & $\Omega_{\mathbf{A}}$ \\
\hline C28 & $28.2 \pm 0.2$ & $2562 \pm 288$ & $2928 \pm 280$ & $8.21 \pm 0.10$ & $483 \pm 86$ & $8.5 \pm 1.2$ & $5.5 \pm 1.2$ \\
C31 & $31.0 \pm 0.6$ & $2375 \pm 283$ & $2738 \pm 278$ & $8.11 \pm 0.13$ & $500 \pm 74$ & $8.1 \pm 1.3$ & $4.8 \pm 1.2$ \\
M28 & $28.0 \pm 0.1$ & $2686 \pm 285$ & $2937 \pm 258$ & $7.95 \pm 0.07$ & $973 \pm 138$ & $5.9 \pm 2.6$ & $3.7 \pm 1.9$ \\
M31 & $30.9 \pm 0.2$ & $2806 \pm 254$ & $3088 \pm 233$ & $7.98 \pm 0.07$ & $953 \pm 131$ & $6.6 \pm 0.5$ & $4.2 \pm 0.6$ \\
H28 & $28.0 \pm 0.2$ & $2858 \pm 430$ & $2908 \pm 456$ & $7.49 \pm 0.11$ & $2934 \pm 898$ & $2.3 \pm 0.4$ & $1.4 \pm 0.4$ \\
H31 & $30.9 \pm 0.1$ & $3231 \pm 281$ & $3294 \pm 324$ & $7.50 \pm 0.10$ & $3431 \pm 810$ & $2.9 \pm 0.4$ & $1.8 \pm 0.5$ \\
\hline
\end{tabular}

\subsection{Identification of Photosymbionts}

The photosymbiont sequences recovered from these A. lobifera represent previously non-sequenced taxa, but phylogenetic analysis as well as BLAST searches confirm that the photosymbionts are a member of the same diatom assemblage as described previously from A. lobifera and other amphisteginids [22,35,52,89]. Molecular fingerprinting of symbionts in the present study revealed that the directly sequenced A. lobifera specimens $(\mathrm{n}=6)$ contained six slightly variable haplotypes (Figure S1) clustering closely with sequences from A. lobifera photosymbionts, collected from the Red and the Mediterranean Sea [22], within the order Fragilariales.

\subsection{Physiological Assessments of Holobiont and Photosymbiont Condition}

\subsubsection{Microelectrode Measurements}

Microsensor measurements showed that $\mathrm{pH}$ at the test surface $\left(\mathrm{pH}_{\mathrm{ts}}\right)$ decreased with increasing $p \mathrm{CO}_{2}$ under all light/temperature conditions (Figure 1b). Furthermore, the difference in proton concentration between seawater and test surface $\left(\Delta\left[\mathrm{H}^{+}\right]=\left[\mathrm{H}^{+}\right]_{\mathrm{sw}}\right.$ $-\left[\mathrm{H}^{+}\right]_{\mathrm{ts}}$ ) significantly affected by $p \mathrm{CO}_{2}$ (PERMANOVA $p=0.003$, Table S3; Figure 1a). Furthermore, there was a significant effect of light/dark condition on $\Delta\left[\mathrm{H}^{+}\right](p=0.021)$. Pairwise comparison of all $\Delta\left[\mathrm{H}^{+}\right]$revealed a significantly higher $\Delta\left[\mathrm{H}^{+}\right]$at high- $p \mathrm{CO}_{2} \times 31^{\circ} \mathrm{C}$ under light (photosynthesis) compared to all other treatments (adjusted $p \leq 0.062$ ), and at high- $p \mathrm{CO}_{2} \times 28^{\circ} \mathrm{C}$ under light compared to moderate- $p \mathrm{CO}_{2} \times 31^{\circ} \mathrm{C}$ under dark (respiration) condition (adjusted $p \leq 0.096$ ). Hence, at high- $p \mathrm{CO}_{2}$, these isolated effects indicated an increase in $\Delta\left[\mathrm{H}^{+}\right]$with light and temperature. The most-elevated $\mathrm{pH}$ at the test surface in comparison to the surrounding water was consequently found at high- $p \mathrm{CO}_{2} \times 31^{\circ} \mathrm{C}$ under light (Figure 1b). 

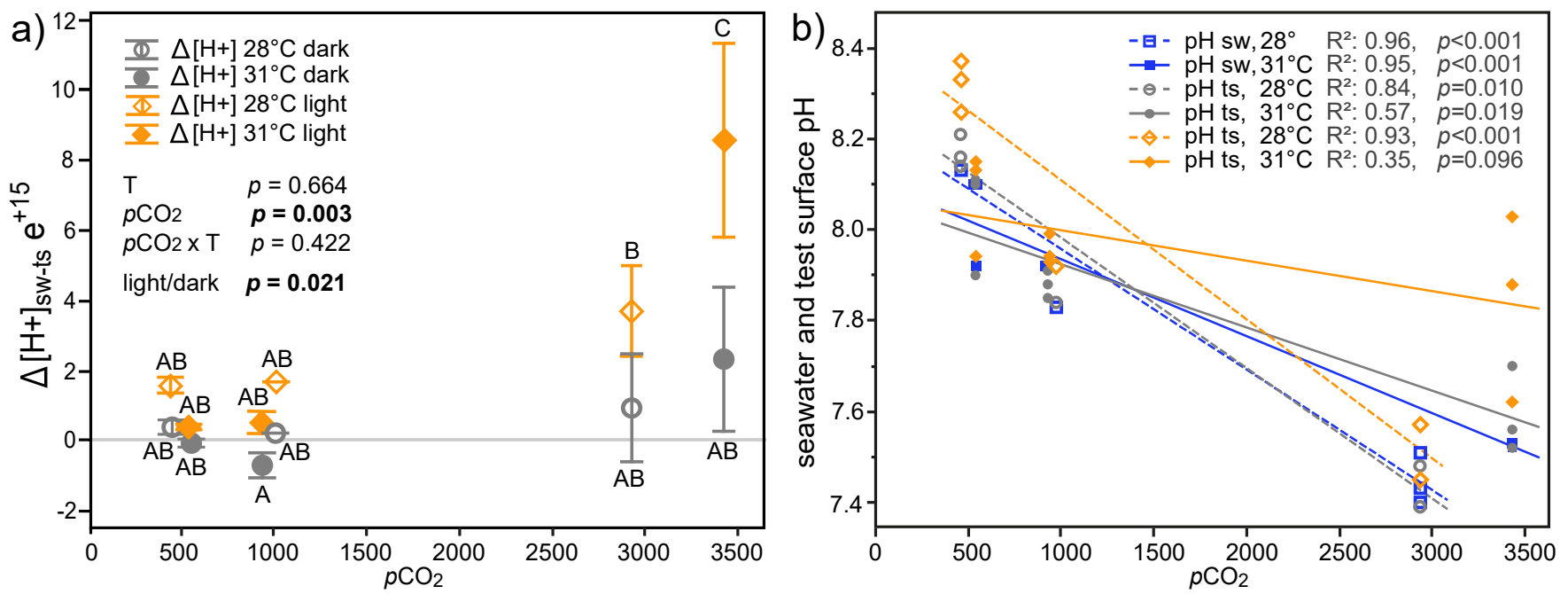

Figure 1. Changes in (a) $\Delta\left[\mathrm{H}^{+}\right]$, i.e., the difference in proton concentration between the seawater (sw) and the test surface $(\mathrm{ts})(\mathrm{n} \leq 3)$ and $(\mathbf{b}) \mathrm{pH}$ at the test surface of Amphistegina lobifera and the seawater (blue rectangles) in response to $p \mathrm{CO}_{2}$ crossed with $28{ }^{\circ} \mathrm{C}$ (open) or $31^{\circ} \mathrm{C}$ (filled), measured by pH microelectrode during exposure to light (yellow diamonds) and dark (grey circles). (a) PERMANOVA $p$-values are given for two-way analysis of the effects of $p \mathrm{CO}_{2}(\mathrm{C}=492 \mathrm{ppm}$, $\mathrm{M}=963 \mathrm{ppm}, \mathrm{H}=3182 \mathrm{ppm}$ ) and temperature $\left(\mathrm{T}: 28^{\circ} \mathrm{C}, 31^{\circ} \mathrm{C}\right)$, as well as for one-way analysis of the effect of light vs. dark. Bold values indicate significant effects $(p<0.05)$. Treatments lacking common capital letters are significantly different in pair-wise comparison of all $\Delta\left[\mathrm{H}^{+}\right]$, corrected for multiple testing at an FDR threshold of 0.1. (b) Lines represent linear regressions for each treatment under light/dark conditions, with $\mathrm{R}^{2}$ indicating coefficient of correlation and respective $p$-values of F-test statistic $(\mathrm{n} \leq 3)$.

\subsubsection{Color and Chlorophyll $a$}

There was no interactive effect of $p \mathrm{CO}_{2}$ and T on $L^{*}, a^{*}$, or $b^{*}$ values, nor on chl $a$ concentration (Figure 2, Table S4). However, there was a significant effect of $p \mathrm{CO}_{2}$ on $b^{*}$ (ANOVA $p=0.040$, Figure 2d). Post-hoc tests suggest a marginally significant (Tukeys $p=0.053)$ color shift from yellower to bluer tones at high- $p \mathrm{CO}_{2}$ compared to control- $p \mathrm{CO}_{2}$ regardless of temperature.

\subsubsection{Holobiont Mortality and Growth}

Holobiont mortality remained low throughout the experiment ranging between $2.9 \%$ in the control $\left(28^{\circ} \mathrm{C}, 492 \mathrm{ppm}\right)$ and $15.2 \%$ at control $-p \mathrm{CO}_{2} \times 31^{\circ} \mathrm{C}$ (Figure $3 \mathrm{c}$ ). There was no significant effect of $p \mathrm{CO}_{2}$ or T on mortality rates throughout the experiment $(p \geq 0.136$; Table S2). There was no interactive effect of $p \mathrm{CO}_{2}$ and $\mathrm{T}(p=0.174)$ on test growth, however, there was a significant reduction in growth under elevated $\mathrm{T}(p=0.038$, Table S4, Figure 3a). 

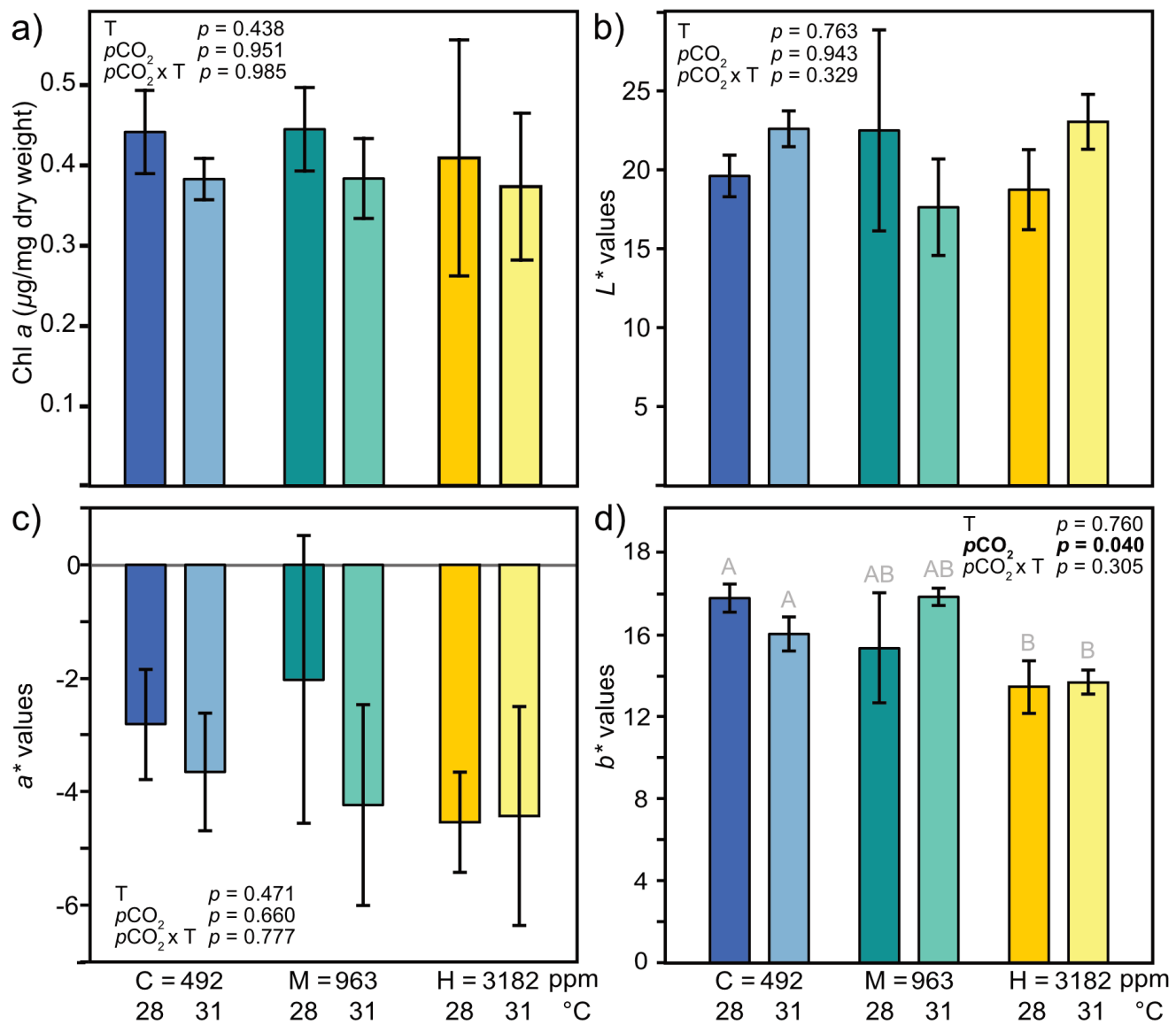

Figure 2. Changes in chlorophyll $a(\mathrm{chl} a)$ and CIE $L^{*} a^{*} b^{*}$ color space values of the Amphistegina lobifera indicate photosymbiont performance in response to elevated $p \mathrm{CO}_{2}(\mathrm{C}=492 \mathrm{ppm}, \mathrm{M}=963 \mathrm{ppm}$, $\mathrm{H}=3182 \mathrm{ppm}$ ) crossed with $28^{\circ} \mathrm{C}$ and $31^{\circ} \mathrm{C}$. (a) $\mathrm{Chl} a$ concentration is a proxy for photosymbiont biomass $(\mathrm{n}=3),(\mathbf{b}) L^{*}$ is a measure of whiteness $(\mathrm{n}=4),(\mathbf{c}) a^{*}$ is a measure of green $(-)$ to magenta $(+)(\mathrm{n}=4)$, and $(\mathrm{d}) b^{*}$ is a measure of blue $(-)$ to yellow $(+)(\mathrm{n}=4)$. Bar plots represent means with standard errors. Two-way ANOVA $p$-values are given in the respective panels, with bold values indicating significant effects. Treatments lacking common capital letters are significantly different in the respective post-hoc multiple comparison (Tukeys' HSD test), with marginal significance if grey.

\subsubsection{Test Surface, Pore Size and Breakage}

No apparent treatment-dependent alterations of test surfaces, such as signs of corrosion, were observed (Figure 4). The frequency of partially broken tests recorded in SE images (Figure 3d) was not significantly impacted by any treatment $(p=0.456,0.610$, and 0.062 for $\mathrm{T}, p \mathrm{CO}_{2}$, and $p \mathrm{CO}_{2} \times \mathrm{T}$, respectively; Table S2). However, the $p$-value for the interaction term is marginally significant (defined as $0.05<p<0.07$ ), suggesting a possible interaction between $p \mathrm{CO}_{2}$ and temperature on breakage frequency. 

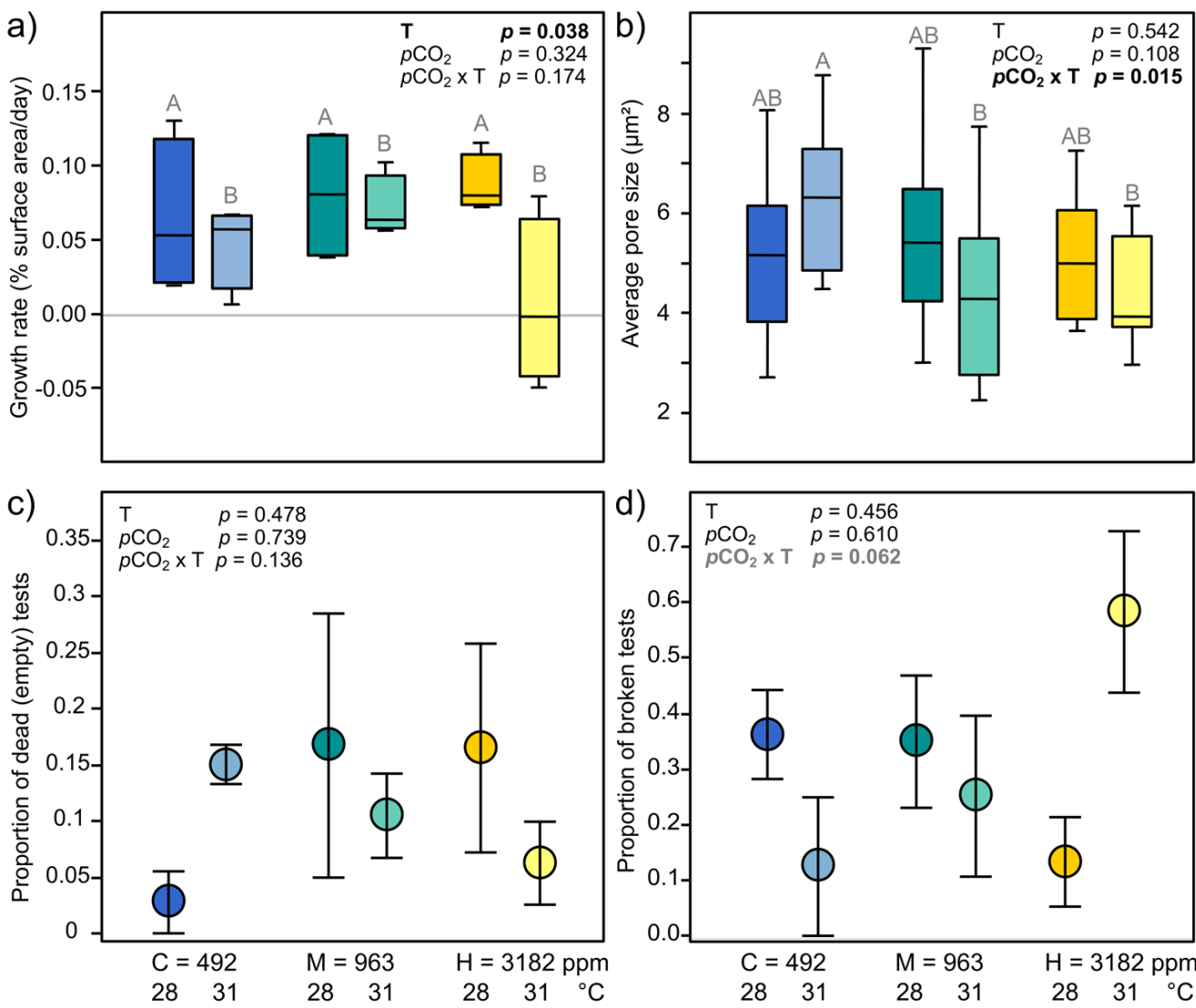

Figure 3. Changes in key physiological parameters of the Amphistegina lobifera host in response to elevated $p \mathrm{CO}_{2}(\mathrm{C}=492 \mathrm{ppm}, \mathrm{M}=963 \mathrm{ppm}, \mathrm{H}=3182 \mathrm{ppm})$ crossed with temperature $\left(28^{\circ} \mathrm{C}, 31^{\circ} \mathrm{C}\right)$ : (a) growth rate calculated as the daily \%-change in total surface area $(n=4),(b)$ average pore sizes of the terminal chambers of their tests $(\mathrm{n} \geq 8),(\mathrm{c})$ mortality represented by proportion of dead (empty) tests, resulting from age-, stress-, and / or reproduction-induced death, and (d) breakage represented by frequency of broken specimens, probably due to reduced test strength. $(\mathbf{a}, \mathbf{b})$ Box plots indicate median and interquartile ranges, with total ranges represented by vertical bars. Two-way ANOVA $p$-values are given, with bold values indicating significant effects $(p \leq 0.05)$. Treatments lacking common capital letters are significantly different in the respective post-hoc multiple comparison (Tukeys' HSD test). (c,d) Dot-and-whisker plots indicate means and standard errors. Logistic model $p$-values for frequency data are given, with marginal significance indicated by grey.

Mean pore size was significantly impacted by the interaction of $p \mathrm{CO}_{2} \times \mathrm{T}(p=0.015$, Figures 2 and 3b). Tukeys' HSD post-hoc analysis shows that at $31^{\circ} \mathrm{C}$, under moderate and high $p \mathrm{CO}_{2}$, pore size was significantly reduced when compared to control- $p \mathrm{CO}_{2}$ conditions (Tukeys' $p=0.030$ and $p=0.040$, respectively; Table S4). 


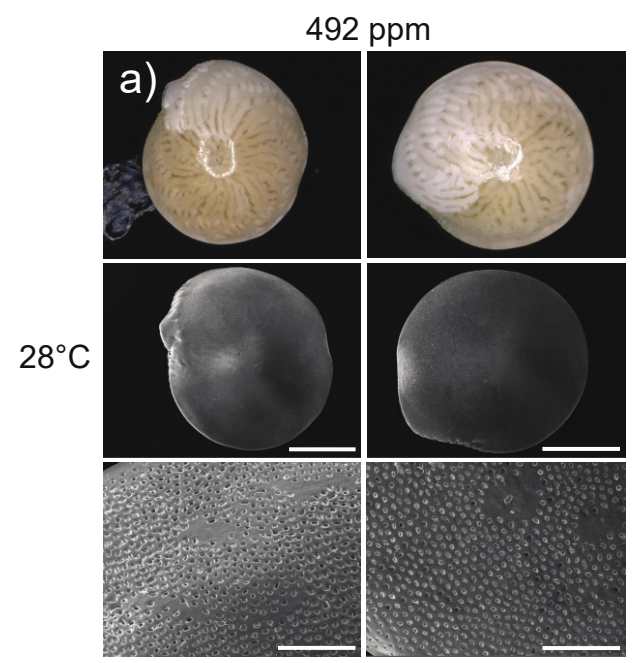

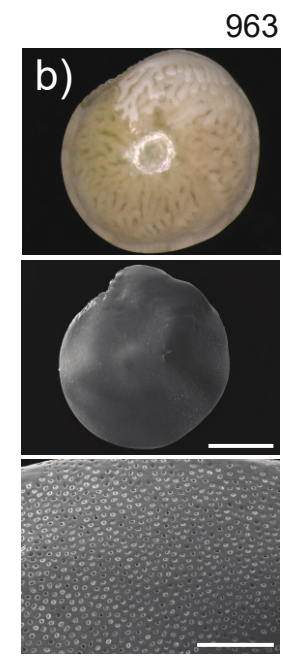

963 ppm
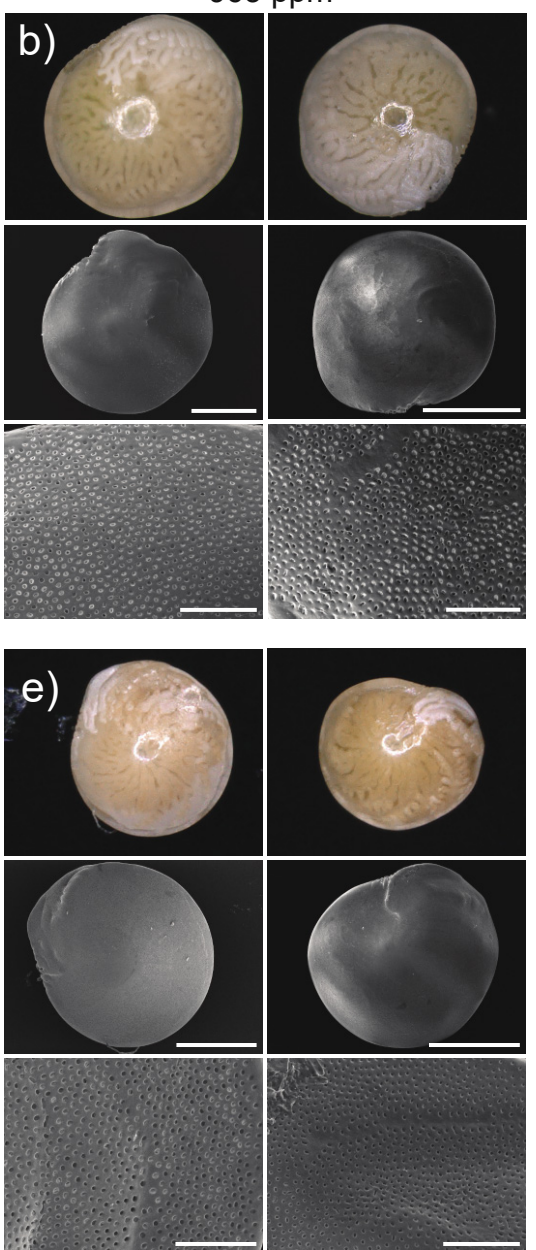
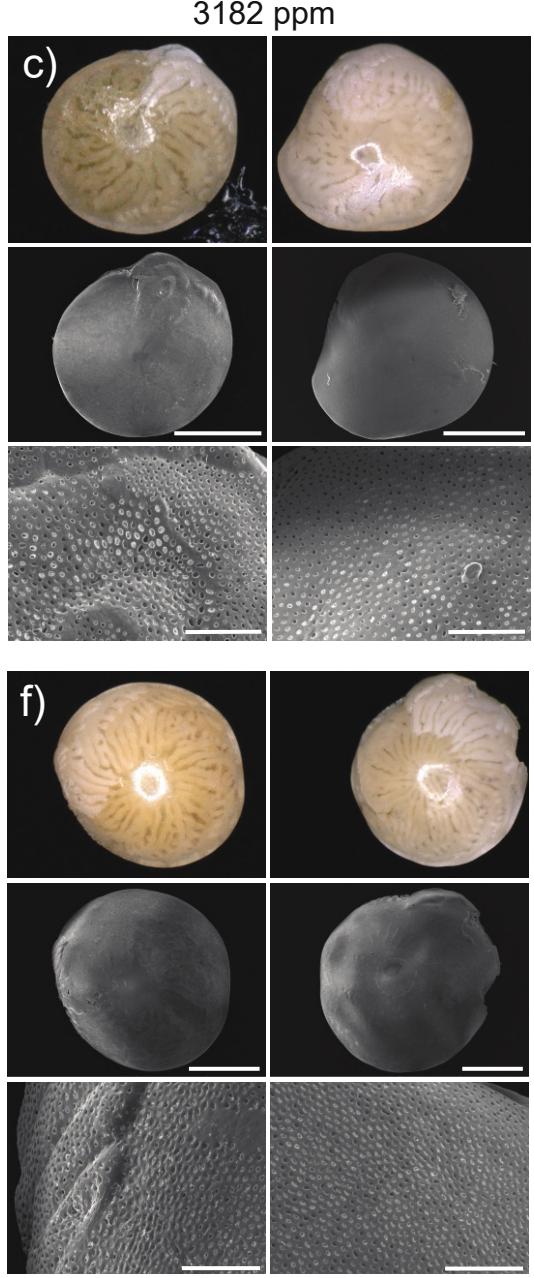

Figure 4. Representative images of Amphistegina lobifera after 8-week exposure to elevated $p \mathrm{CO}_{2}$ (control = 492 ppm, a,d; moderate $=963 \mathrm{ppm}, \mathbf{b}, \mathbf{e} ;$ high $=3182 \mathrm{ppm}, \mathbf{c}, \mathbf{f})$ crossed with temperature $\left(28^{\circ} \mathrm{C}, \mathbf{a}-\mathbf{c} ; 31^{\circ} \mathrm{C}, \mathbf{d}-\mathbf{f}\right)$. Entire specimens shown via light microscopy (upper rows) and low-magnification SE imaging (middle rows), with the terminal chamber shown via high-magnification SE imaging. Scale bars in the full-specimen images represent $500 \mu \mathrm{m}$, while bars in high-magnification images represent $50 \mu \mathrm{m}$.

\subsection{Proteomics}

\subsubsection{Label-Free Peptide Quantification and Protein Identification}

A total of 1103 protein clusters (i.e., groups of proteins with $\geq 70 \%$ sequence identity) were detected and identified from $A$. lobifera and its photosymbiotic diatoms (Table S5). Fifteen of these clusters were comprised of specific protein sequences belonging to tubulins, actin, heat shock proteins (HSPs), and peptidyl-prolyl cis-trans isomerase, from both the host and photosymbionts. Approximately $40 \%$ of the protein clusters (hereafter referred to as 'proteins') were assigned to the photosymbionts, whereas $60 \%$ were associated with the host foraminifera (Figure 5a). The relative proportion of host and symbiont proteins was relatively stable across treatments. The only successfully recovered sample from the control treatment (control- $p \mathrm{CO}_{2} \times 28{ }^{\circ} \mathrm{C}$ ) was removed from further analyses due to the lack of replication. 
a)

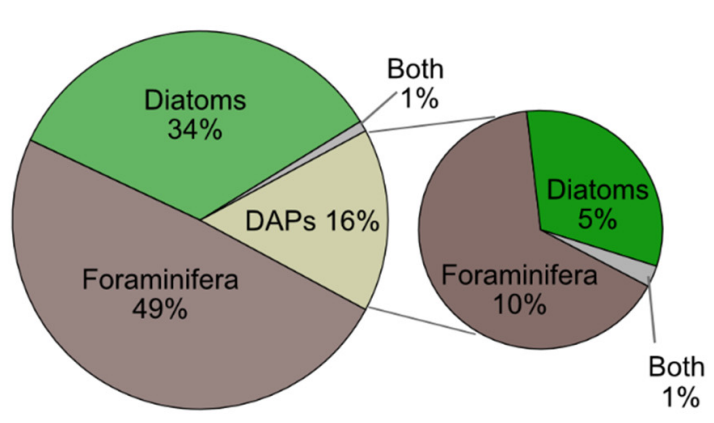

b)

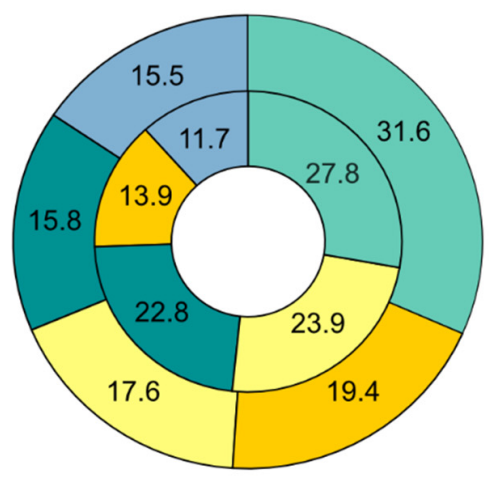

c)

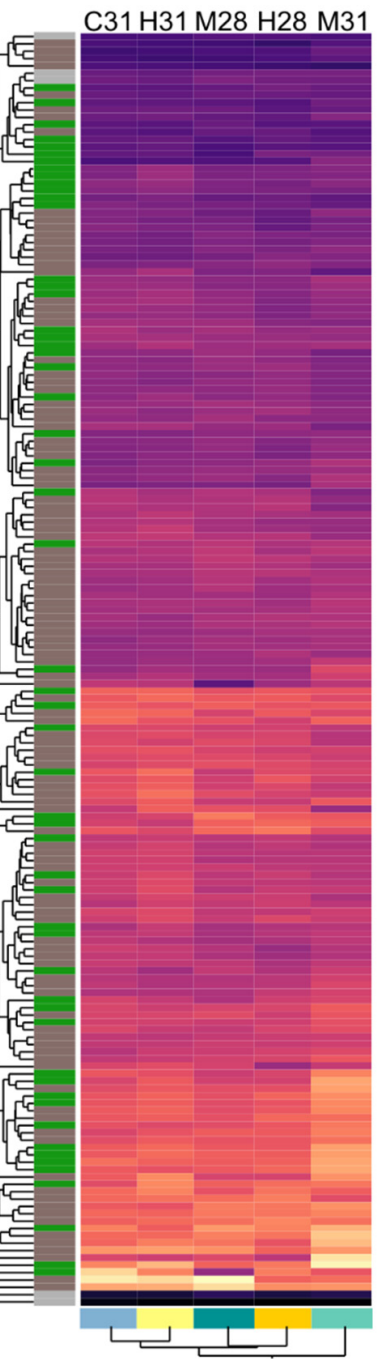

d)

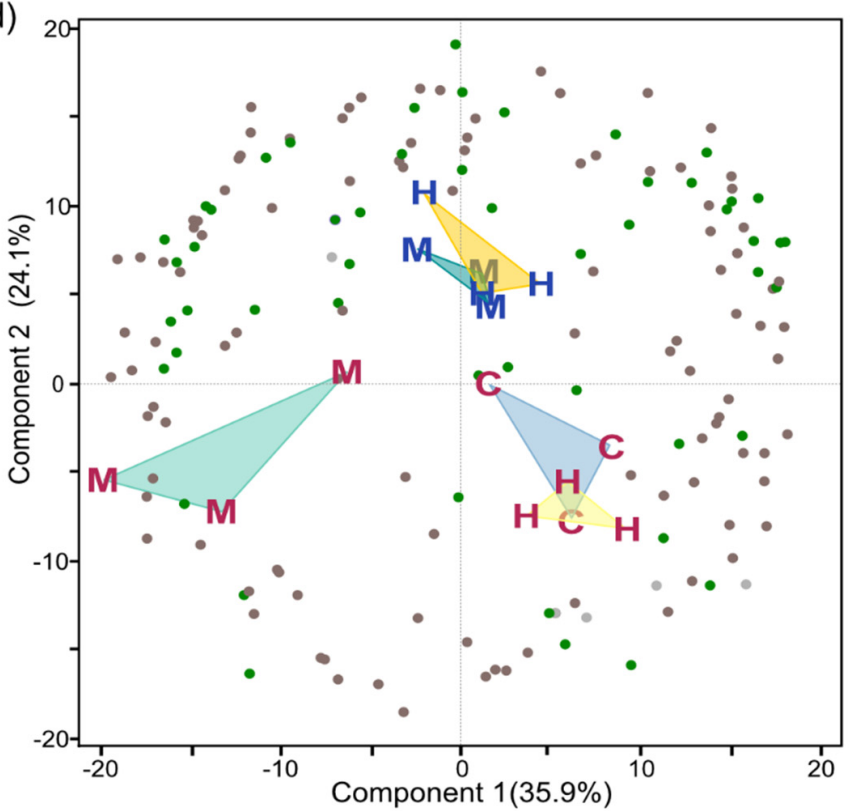

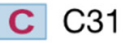

M M28

M M31

H $\mathrm{H} 28$

H H31

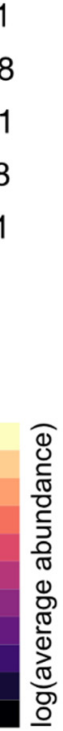

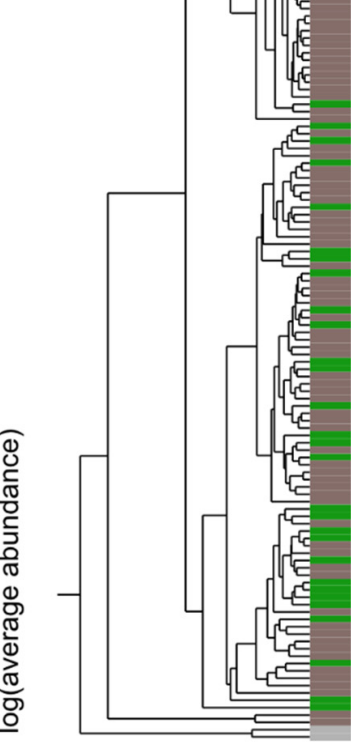

\section{.}

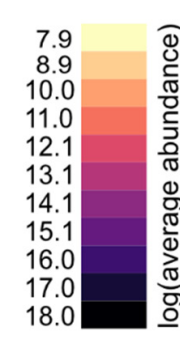

Figure 5. Summary of the proteomic results: (a) proportion of all identified proteins $(\mathrm{n}=1103)$ and differentially abundant
proteins (DAPs, $\mathrm{n}=173$ ) in Amphistegina lobifera holobionts that were assigned to the foraminiferal host, their photosymbiotic diatoms, or both; (b) proportion of DAPs per treatment of elevated $p \mathrm{CO}_{2}(\mathrm{C}=492 \mathrm{ppm}, \mathrm{M}=963 \mathrm{ppm}, \mathrm{H}=3182 \mathrm{ppm})$ at $28{ }^{\circ} \mathrm{C}$ or $31{ }^{\circ} \mathrm{C}$ in the host (outer) and the photosymbionts (inner); (c) hierarchical cluster analyses based on average linkage and heatmap where rows represent DAPs and columns represent the log-transformed average of three replicates per treatments, and the left column indicates if the protein was associated with the host (brown), photosymbionts (green), or both (grey); (d) principal component analysis biplot on correlation of all DAPs, with letters connected by triangles indicating the replicate samples of each treatment combination of different $p \mathrm{CO}_{2}$ at control (blue) or high (red) temperature, and dots indicating the DAPs (colors as in (c)) as loading variables.

Permutational multivariate analyses of variance conducted on all proteins, as well as only those associated with either host or photosymbionts, all indicated significant single effects of $p \mathrm{CO}_{2}$ or T (2-way PERMANOVA, $p=0.030$ and 0.018 , respectively, Table 2) and no interactive effects. However, adjusted $p$-values of post-hoc pairwise comparisons were non-significant. Nevertheless, the effect of $\mathrm{T}$ was overall more significant than the effect of $p \mathrm{CO}_{2}$, especially for the photosymbionts. 
Table 2. Results of permutational multivariate analysis of variance (PERMANOVA) for all proteins, and for only host or only photosymbiont proteins of Amphistegina lobifera exposed to elevated $p \mathrm{CO}_{2}$ ( $\mathrm{C}=492$ ppm, $\mathrm{M}=963 \mathrm{ppm}, \mathrm{H}=3182 \mathrm{ppm}$ ) crossed with temperature (Temp.: $28^{\circ} \mathrm{C}, 31^{\circ} \mathrm{C}$ ) for eight weeks. Pairwise comparisons of significant effects were per performed with $p$-values adjusted for multiple testing. Bold font indicates statistical significance $(p \leq 0.05)$.

\begin{tabular}{|c|c|c|c|c|c|}
\hline Proteins & DF & MS & $\mathbf{F}$ & $\operatorname{Pr}(>F)$ & Post-Hoc Test Summary \\
\hline \multicolumn{6}{|l|}{ Holobiont } \\
\hline$p \mathrm{CO}_{2}$ & 2 & 0.0003 & 1.818 & 0.028 & H:C 0.480, M:C 0.290, H:M 0.130 \\
\hline Temp. & 1 & 0.0004 & 2.335 & 0.013 & $31^{\circ} \mathrm{C}: 28^{\circ} \mathrm{C} 0.080$ \\
\hline$p \mathrm{CO}_{2} \times$ Temp & 1 & 0.0003 & 1.719 & 0.075 & \\
\hline \multicolumn{6}{|l|}{ Foraminifera } \\
\hline$\overline{p \mathrm{CO}_{2}}$ & 2 & 0.0003 & 1.854 & 0.030 & H:C 0.390 M:C 0.270, H:M 0.170 \\
\hline Temp. & 1 & 0.0004 & 2.358 & 0.018 & $31^{\circ} \mathrm{C}: 28^{\circ} \mathrm{C} 0.079$ \\
\hline$p \mathrm{CO}_{2} \times$ Temp & 1 & 0.0003 & 1.697 & 0.091 & \\
\hline \multicolumn{6}{|l|}{ Photosymbiont } \\
\hline$\overline{p \mathrm{CO}_{2}}$ & 2 & 0.0004 & 1.775 & 0.030 & H:C 0.607, M:C 0.321, H:M 0.091 \\
\hline Temp. & 1 & 0.0005 & 2.324 & 0.011 & $31^{\circ} \mathrm{C}: 28^{\circ} \mathrm{C} 0.089$ \\
\hline$p \mathrm{CO}_{2} \times$ Temp & 1 & 0.0004 & 1.734 & 0.067 & \\
\hline
\end{tabular}

\subsubsection{Differential Abundant Protein (DAP) Distribution in Treatments and Compartments}

We employed a GLM using the five remaining 'treatment' combinations as single factors to detect significant differences in protein abundance. In total, 173 proteins were significantly differently abundant between treatments $(q<0.05$, Table S6). Of these DAPs, 55 were from the symbiont, 113 were from the host, and 5 were assigned to both (Figure 5a). Hence, the proportion of differentially abundant host proteins was significantly higher than that of photosymbiont proteins (2-tailed Fisher's exact test, $p=0.049$ ). Most significant differences were found between moderate- $p \mathrm{CO}_{2} \times 31^{\circ} \mathrm{C}$ in contrast to all other treatments in both compartments, and least at control- $p \mathrm{CO}_{2} \times 31{ }^{\circ} \mathrm{C}$ (Figure 5b, Table S7). Second highest percentage of DAPs in the host was found in response to high- $p \mathrm{CO}_{2} \times{ }^{\circ} \mathrm{C}$, while it was comparably low in the photosymbionts, where high- $p \mathrm{CO}_{2} \times 31$ caused the second most DAPs.

Multivariate analyses of all DAPs confirmed this distinction of the moderate- $p \mathrm{CO}_{2} \times 31^{\circ} \mathrm{C}$ treatment, and further illustrated high similarities among protein abundance patterns of control- $p \mathrm{CO}_{2} \times 31^{\circ} \mathrm{C}$ and high- $p \mathrm{CO}_{2} \times 31^{\circ} \mathrm{C}$ treatments, as well as moderate- $p \mathrm{CO}_{2} \times 28{ }^{\circ} \mathrm{C}$ and high- $p \mathrm{CO}_{2} \times 28^{\circ} \mathrm{C}$ treatments (Figure $5 \mathrm{c}$ ). The strong overlap between samples of these treatments led to partial clustering of alike samples (Figure S2). However, the distinction of moderate- $p \mathrm{CO}_{2} \times 31^{\circ} \mathrm{C}$ from all other treatments and the otherwise main grouping by temperature were evident throughout, as well as when host and photosymbiont DAPs were analyzed separately (Figures S3 and S4). Principal component analysis (PCA) showed that $35.9 \%$ of overall variations were explained by the differentiation along the $x$-axis, which mainly differentiated moderate- $p \mathrm{CO}_{2} \times 31^{\circ} \mathrm{C}$ from all other treatments, while $24.1 \%$ were explained by the separation of temperature treatment groups along the $y$-axis (Figure $5 \mathrm{~d}$ ). In moderate- $p \mathrm{CO}_{2} \times 31{ }^{\circ} \mathrm{C}$, most proteins were less abundant, but those clustering close to this treatment were highly abundant and mostly host-associated. The differentiation between $31{ }^{\circ} \mathrm{C}$ and $28{ }^{\circ} \mathrm{C}$ was associated with overall reduced protein abundances in the host and, particularly, the photosymbionts, as most proteins clustered in the upper half of the diagram (Figure $5 \mathrm{~d}$ and Figure S6).

The origin of the most abundant proteins, beta tubulin and polyubiquitin, could not be determined due to their strong homology among organisms. Also, three other highly conserved and abundant proteins [actin, heat shock protein (HSP) 90, and ADP-ribosylation factor] could not be clearly associated to either host or photosymbionts. Polyubiquitin increased with $p \mathrm{CO}_{2}$, but not at $31{ }^{\circ} \mathrm{C}$. In contrast, the other four proteins were most abundant in control- and high- $p \mathrm{CO}_{2} \times 31^{\circ} \mathrm{C}$, but not at moderate- $p \mathrm{CO}_{2} \times 31^{\circ} \mathrm{C}$. HSP90 and ADP-ribosylation factor, which are responsible for protein folding and transport, also 
showed increases at high-compared to moderate- $p \mathrm{CO}_{2}$ at $28{ }^{\circ} \mathrm{C}$ and $31^{\circ} \mathrm{C}$, respectively (Figure S2, Table S6). All proteins of unclear origin were removed from downstream analyses. Separate analyses of host and photosymbiont-associated DAPs showed overall alike patterns of protein variations (Figures S3-S6). Differences were mainly found for moderate- $p \mathrm{CO}_{2} \times 28^{\circ} \mathrm{C}$, which was overall most similar to the other $28^{\circ} \mathrm{C}$ treatment in the host, but highly similar to control- $p \mathrm{CO}_{2} \times 31^{\circ} \mathrm{C}$ in the photosymbionts. Generally, there was a further separation along the $y$-axis in the photosymbiont, showing more distinct proteome variations of moderate- $p \mathrm{CO}_{2} \times 28{ }^{\circ} \mathrm{C}$ and high- $p \mathrm{CO}_{2} \times 31{ }^{\circ} \mathrm{C}$ in comparison to the host.

\subsubsection{Functional Categories of Photosymbiont- and Host-Associated DAPs}

The gene ontology analysis of DAPs revealed the biological processes, molecular functions, and cellular components these proteins are involved in (Table S6, Figures S3 and S4). The 97 most strongly regulated proteins (i.e., DAPs that also showed $\log _{2} \mathrm{FC} \geq|1|$ between treatments with Tukeys' $p \leq 0.05$ ) were grouped by major functional categories based on GO annotations and summarized (Tables 3 and 4). PCAs of total DAP abundances per functional category revealed the underlying contribution of these groups driving the proteomic differences between treatments (Figure 6).
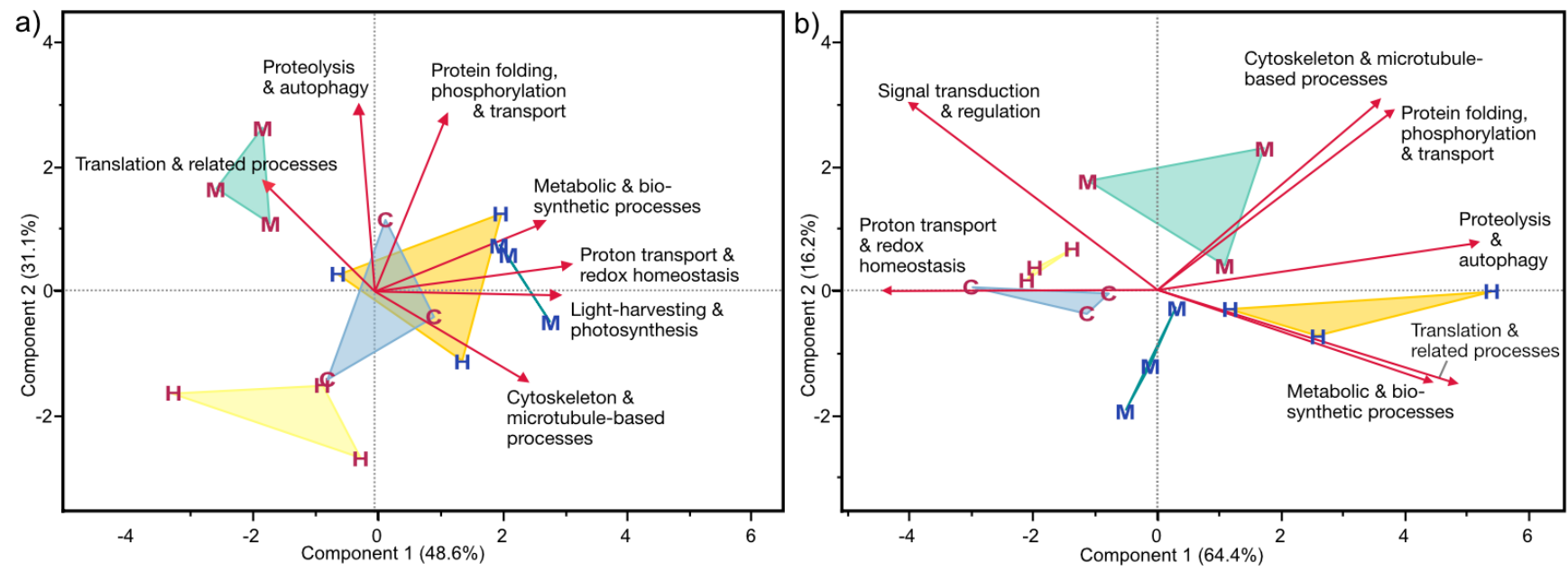

Figure 6. Principal component analyses of total normalized abundance values of the functional categories of (a) photosymbiont- and (b) host-associated DAPs in Amphistegina lobifera exposed to treatments of elevated $p \mathrm{CO}_{2}\left({ }^{\prime} \mathrm{C}^{\prime}=492 \mathrm{ppm}\right.$, ${ }^{\prime} \mathrm{M}^{\prime}=963 \mathrm{ppm}, \mathrm{H}^{\prime}=3182 \mathrm{ppm}$ ) at $28^{\circ} \mathrm{C}$ (blue) or $31^{\circ} \mathrm{C}$ (red). Arrows indicate the direction and intensity of functional categories driving differences between the treatments, with triangles connecting the triplicate samples of each treatment (legend as in Figure 5).

In the photosymbionts, a separation along the $x$-axis explained $48.6 \%$ of the variation, mostly separating $31{ }^{\circ} \mathrm{C}$ from $28^{\circ} \mathrm{C}$ treatments (Figure 6a). High $\mathrm{T}\left(31^{\circ} \mathrm{C}\right)$ dominantly caused decreases of proteins involved in light-harvesting and photosynthesis, proton transport or cell redox homeostasis, metabolic and (fatty acid or other) biosynthetic processes, but also cytoskeleton (development) and protein transport decreased, while some proteins involved in translation, protein folding, biosynthetic processes, and proton transmembrane transport showed increases. High- $p \mathrm{CO}_{2} \times 31^{\circ} \mathrm{C}$ led to a decrease of enzymes involved in fatty-acid and other biosynthetic processes, whereas proteins responsible for protein folding increased. At moderate- $p \mathrm{CO}_{2} \times 31{ }^{\circ} \mathrm{C}$, stronger decreases were found, specifically of proteins involved in photosynthetic light-harvesting, (carbohydrate) metabolism, biosynthetic, and transport processes. At moderate- $\mathrm{CCO}_{2} \times 28^{\circ} \mathrm{C}$, some proteins of photosystem I, or involved in metabolism (e.g., the citric acid cycle) and cytoskeleton development-related processes were relatively elevated (Table 3 ). 
Table 3. Regulated proteins of photosymbionts of Amphistegina lobifera in response to elevated $p \mathrm{CO}_{2}$ (' $\mathrm{C}^{\prime}=492 \mathrm{ppm}$, $' \mathrm{M}^{\prime}=963 \mathrm{ppm},{ }^{\prime} \mathrm{H}^{\prime}=3182 \mathrm{ppm}$ ) at $28^{\circ} \mathrm{C}$ or $31^{\circ} \mathrm{C}$, without the $\mathrm{C} 28$ treatment (GLM, $q \leq 0.05$, Tukeys' $p \leq 0.05$, and $\log _{2} \mathrm{FC}$ $\geq|1|$ ). Proteins are arranged by their major functions and processes according to GO terms, however, these roles are not exclusive as many proteins can have various functions. Directions and intensities of $\log _{2} \mathrm{FC}$ are illustrated by color, significant differences in average protein abundance between treatments are denoted in bold. Respective annotated gene ontologies, accession numbers, and remaining DAPs are provided in Table S6.

\begin{tabular}{|c|c|c|c|c|c|c|c|c|c|c|}
\hline \multirow[b]{2}{*}{ Protein Description } & \multicolumn{10}{|c|}{$\log _{2}$ (Fold-Change) } \\
\hline & $\begin{array}{l}\text { M31/ } \\
\text { M28 }\end{array}$ & $\begin{array}{l}\text { H31/ } \\
\text { H28 }\end{array}$ & $\begin{array}{l}\text { H28/ } \\
\text { M28 }\end{array}$ & $\begin{array}{l}\text { H31/ } \\
\text { M31 }\end{array}$ & $\begin{array}{c}\text { M31/ } \\
\text { C31 }\end{array}$ & $\begin{array}{c}\text { H31/ } \\
\text { C31 }\end{array}$ & $\begin{array}{c}\text { M31/ } \\
\text { H28 }\end{array}$ & $\begin{array}{l}\text { C31/ } \\
\text { M28 }\end{array}$ & $\begin{array}{l}\text { H31/ } \\
\text { M28 }\end{array}$ & $\begin{array}{l}\text { C31/ } \\
\text { H28 }\end{array}$ \\
\hline \multicolumn{11}{|l|}{ Light-harvesting and photosynthesis } \\
\hline protein fucoxanthin chlorophyll $a / c$ & -2.34 & -0.27 & 0.05 & 2.11 & -2.63 & -0.51 & -2.38 & 0.29 & -0.22 & 0.24 \\
\hline protein fucoxanthin chlorophyll $a / c$ & -1.90 & 0.15 & -0.19 & 1.86 & -2.12 & -0.25 & -1.71 & 0.21 & -0.04 & 0.40 \\
\hline divinyl chlorophyllidea 8-vinyl-reduct. & -2.60 & 0.81 & -0.48 & 2.93 & -2.56 & 0.37 & -2.12 & -0.04 & 0.33 & 0.44 \\
\hline thylakoid lumenal $15.0 \mathrm{kDa}$ protein 2 & -1.03 & -0.09 & -0.16 & 0.78 & -0.76 & 0.02 & -0.87 & -0.28 & -0.25 & -0.12 \\
\hline cytochrome b6/f complex subunit IV & -3.18 & -0.17 & -4.64 & -1.64 & 4.27 & 2.63 & 1.46 & -7.45 & -4.81 & -2.81 \\
\hline \multicolumn{11}{|l|}{ Metabolic and biosynthetic processes } \\
\hline$\overline{\text { uroporphyrinogen decarboxylase }}$ & -4.78 & -2.04 & -0.75 & 1.99 & -3.61 & -1.62 & -4.03 & -1.16 & -2.79 & -0.41 \\
\hline fructose-bisphosphate aldolase & -2.03 & -0.51 & 0.11 & 1.63 & -2.28 & -0.65 & -2.14 & 0.25 & -0.40 & 0.14 \\
\hline demethylmenaquinone methyltransfer. & -2.36 & -0.71 & 0.11 & 1.75 & -2.24 & -0.49 & -2.46 & -0.12 & -0.60 & -0.22 \\
\hline 3-isopropylmalate dehydrogenase & -2.94 & -0.52 & -0.51 & 1.90 & -1.56 & 0.34 & -2.43 & -1.38 & -1.04 & -0.87 \\
\hline glucose-6-phosphate isomerase & -1.14 & 0.47 & -0.09 & 1.53 & -1.08 & 0.44 & -1.05 & -0.05 & 0.39 & 0.03 \\
\hline cysteine desulfurase & -0.26 & 0.54 & 0.65 & 1.46 & -0.58 & 0.88 & -0.91 & 0.32 & 1.19 & -0.34 \\
\hline taurine catabolism dioxygenase TauD & -0.75 & -0.88 & -0.51 & -0.63 & -1.58 & -2.21 & -0.25 & 0.82 & -1.39 & 1.33 \\
\hline alanine dehydrogenase 2 & -1.00 & -0.43 & 0.03 & 0.60 & -0.47 & 0.12 & -1.03 & -0.52 & -0.40 & -0.55 \\
\hline inorganic pyrophosphatase & -0.72 & -0.44 & 0.30 & 0.58 & -0.61 & -0.03 & -1.02 & -0.12 & -0.14 & -0.41 \\
\hline inorganic pyrophosphatase & -0.79 & -0.63 & -0.03 & 0.13 & 0.00 & 0.13 & -0.76 & -0.79 & -0.66 & -0.76 \\
\hline phosphoadenosine-phosphosulphate red. & -0.36 & -1.08 & 0.27 & -0.45 & 0.11 & -0.33 & -0.63 & -0.47 & -0.81 & -0.75 \\
\hline S-adenosylmethionine synthase 2 & 0.65 & -0.25 & 0.20 & -0.70 & 1.03 & 0.33 & 0.45 & -0.38 & -0.05 & -0.58 \\
\hline geranylgeranyl reductase & 0.57 & -0.41 & -0.13 & -1.11 & 1.04 & -0.07 & 0.70 & -0.47 & -0.53 & -0.34 \\
\hline carbamoyl-phosphate synthase & -0.62 & -0.75 & -0.41 & -0.53 & -0.45 & -0.98 & -0.22 & -0.17 & -1.15 & 0.24 \\
\hline acetyl-coa carboxylase & -0.46 & -1.05 & -0.11 & -0.71 & -0.25 & -0.96 & -0.34 & -0.21 & -1.17 & -0.09 \\
\hline acetyl-coa carboxylase & -0.20 & -1.04 & -0.09 & -0.93 & -0.15 & -1.08 & -0.11 & -0.05 & -1.13 & 0.04 \\
\hline ALA dehydratase & -0.55 & -0.95 & -0.72 & -1.12 & 0.30 & -0.82 & 0.17 & -0.85 & -1.67 & -0.13 \\
\hline agmatinase & -1.54 & 0.40 & -1.19 & 0.75 & -0.10 & 0.65 & -0.35 & -1.44 & -0.79 & -0.24 \\
\hline glutamate synthase 2 [NADH] & -0.65 & -1.42 & -0.97 & -1.74 & 0.87 & -0.87 & 0.32 & -1.52 & -2.40 & -0.55 \\
\hline aspartate-ammonia ligase & 1.66 & 0.16 & 0.30 & -1.20 & 1.74 & 0.54 & 1.36 & -0.09 & 0.45 & -0.38 \\
\hline \multicolumn{11}{|c|}{ Proton transmembrane transport, cell redox homeostasis and cellular detoxification } \\
\hline thioredoxin & -1.08 & 0.38 & -0.28 & $\overline{1.18}$ & -1.65 & -0.47 & -0.80 & 0.56 & 0.10 & 0.85 \\
\hline L-ascorbate peroxidase & -0.17 & -1.11 & 0.45 & -0.50 & 0.16 & -0.34 & -0.62 & -0.32 & -0.66 & -0.77 \\
\hline \multicolumn{11}{|l|}{ Protein folding, phosphorylation and transport } \\
\hline translocation protein sec62 & -2.44 & 0.03 & -0.18 & 2.28 & -1.74 & 0.54 & -2.25 & -0.69 & -0.16 & -0.51 \\
\hline T-complex prote & -0.77 & 1.25 & 0.75 & 2.77 & -1.53 & 1.24 & -1.52 & 0.76 & 2.00 & 0.01 \\
\hline leucine-rich repeat-containing pro & 1.32 & 1.07 & 1.13 & 0.88 & -1.27 & -0.39 & 0.19 & 2.59 & 2.20 & 1.46 \\
\hline ATP-dependent chaperone ClpB & 1.29 & 0.12 & 0.34 & -0.83 & 0.84 & 0.00 & 0.95 & 0.46 & 0.46 & 0.11 \\
\hline luminal-binding protein 5 & 0.22 & -0.56 & -0.24 & -1.03 & 0.67 & -0.36 & 0.46 & -0.45 & -0.81 & -0.21 \\
\hline \multicolumn{11}{|l|}{ Proteolysis and autophagy } \\
\hline Clp protease ATP binding subunit & 0.37 & -0.39 & -0.27 & -1.04 & 0.42 & -0.62 & 0.64 & -0.05 & -0.67 & 0.23 \\
\hline \multicolumn{11}{|l|}{ Translation and related process } \\
\hline 40S ribosomal protein & 0.24 & -0.72 & -0.52 & -1.49 & 0.76 & -0.73 & 0.77 & -0.51 & -1.24 & 0.01 \\
\hline \multicolumn{11}{|l|}{ Cytoskeleton and microtubule-based processes } \\
\hline cell division protein FtsZ & -2.18 & 0.06 & -0.86 & 1.38 & -1.92 & -0.54 & -1.32 & -0.26 & -0.80 & 0.60 \\
\hline tubulin-specific chaperone $\mathrm{d}$ & -2.15 & -0.40 & -0.34 & 1.42 & -1.78 & -0.37 & -1.82 & -0.37 & -0.74 & -0.04 \\
\hline \multicolumn{11}{|l|}{ Unknown functions } \\
\hline hypothetical protein & -1.54 & 0.78 & -1.74 & 0.57 & -0.64 & -0.06 & 0.21 & -0.90 & -0.96 & 0.84 \\
\hline
\end{tabular}


In the host, the impact of these functional protein groups on treatment differentiation was even stronger (Figure $6 \mathrm{~b}$ ). Elevated temperature $\left(31^{\circ} \mathrm{C}\right)$ caused general decreases of ribosomal and other translation-related proteins, and various metabolic (catalytic) enzymes (e.g., those involved in the citric acid cycle, pentose-phosphate pathway, and electron transport). Likewise, some proteasomal and proteins involved in the regulation of protein folding or ubiquitination, cytoskeleton organization, or microtubule-based movement, decreased. In contrast, some proteins responsible for protein (re-)folding and degradation (proteasome subunits), and microtubule-based transport processes, increased, especially at moderate $-p \mathrm{CO}_{2} \times 31^{\circ} \mathrm{C}$. In comparison, proteins responsible for (transmembrane) ion transport or signal transduction were particularly increased at control- and high- $p \mathrm{CO}_{2} \times 31^{\circ} \mathrm{C}$. Several proteasomal, metabolic and biosynthetic proteins were increased with $p \mathrm{CO}_{2}$, especially at high- $p \mathrm{CO}_{2} \times 28^{\circ} \mathrm{C}$, whereas proton transporters seemed to decrease under that treatment (Table 4).

Table 4. Regulated proteins of host foraminifera Amphistegina lobifera in response to elevated $p \mathrm{CO}_{2}$ (' $\mathrm{C}^{\prime}=492 \mathrm{ppm}$, ${ }^{\prime} \mathrm{M}$ ' $=963 \mathrm{ppm}$, and ' $\mathrm{H}^{\prime}=3182 \mathrm{ppm}$ ) at $28^{\circ} \mathrm{C}$ or $31^{\circ} \mathrm{C}$, without the $\mathrm{C} 28$ treatment (GLM, $q \leq 0.05$, Tukeys' $p \leq 0.05$, and $\log _{2} \mathrm{FC} \geq|1|$ ). Proteins are arranged by their major functions and processes according to GO terms; however, these roles are not exclusive as many proteins can have various functions. Directions and intensities of $\log _{2} \mathrm{FC}$ are illustrated by color, significant differences in average protein abundance between treatments are denoted in bold. Respective annotated gene ontologies, accession numbers, and remaining DAPs are provided in Table S6.

\begin{tabular}{|c|c|c|c|c|c|c|c|c|c|c|}
\hline \multirow[b]{2}{*}{ Protein Description } & \multicolumn{10}{|c|}{$\log _{2}$ (Fold-Change) } \\
\hline & $\begin{array}{l}\text { M31/ } \\
\text { M28 }\end{array}$ & $\begin{array}{l}\text { H31/ } \\
\text { H28 }\end{array}$ & $\begin{array}{l}\text { H28/ } \\
\text { M28 }\end{array}$ & $\begin{array}{l}\text { H31/ } \\
\text { M31 }\end{array}$ & $\begin{array}{c}\text { M31/ } \\
\text { C31 }\end{array}$ & $\begin{array}{c}\text { H31/ } \\
\text { C31 }\end{array}$ & $\begin{array}{l}\text { M31/ } \\
\text { H28 }\end{array}$ & $\begin{array}{l}\text { C31/ } \\
\text { M28 }\end{array}$ & $\begin{array}{l}\text { H31/ } \\
\text { M28 }\end{array}$ & $\begin{array}{l}\text { C31/ } \\
\text { H28 }\end{array}$ \\
\hline \multicolumn{11}{|l|}{ Signal transduction and regulation } \\
\hline $\begin{array}{l}\text { NEDD8-activating enzyme E1 regulat. } \\
\text { cullin-associated NEDD8-dissociated } 1 \\
\text { Ras-related protein Rab-21 } \\
\text { GTPase HRas } \\
\text { Ras-related protein Rab-7a-like } \\
\text { cytochrome c oxidase assembly (SCO) } \\
\text { guanine nucleotide-binding protein G }\end{array}$ & $\begin{array}{l}-2.34 \\
-1.17 \\
-1.08 \\
-0.69 \\
\mathbf{- 1 . 3 7} \\
\mathbf{- 1 . 1 2} \\
\mathbf{- 1 . 1 1}\end{array}$ & $\begin{array}{l}0.42 \\
0.28 \\
0.55 \\
1.33 \\
0.74 \\
0.32 \\
0.35\end{array}$ & $\begin{array}{c}0.35 \\
0.09 \\
-0.15 \\
0.14 \\
-0.83 \\
-0.28 \\
-0.96\end{array}$ & $\begin{array}{l}3.11 \\
1.53 \\
1.48 \\
2.15 \\
1.28 \\
1.15 \\
0.50\end{array}$ & \begin{tabular}{l|}
-3.08 \\
-2.20 \\
-1.76 \\
-1.84 \\
-1.34 \\
-0.92 \\
-0.79
\end{tabular} & $\begin{array}{c}0.03 \\
-0.66 \\
-0.27 \\
0.31 \\
-0.05 \\
0.23 \\
-0.29\end{array}$ & $\begin{array}{l}-2.69 \\
-1.26 \\
-0.93 \\
-0.82 \\
-0.55 \\
-0.84 \\
-0.15\end{array}$ & $\begin{array}{l}0.74 \\
1.03 \\
0.68 \\
1.16 \\
-0.04 \\
-0.20 \\
-0.32\end{array}$ & $\begin{array}{c}0.77 \\
0.37 \\
0.40 \\
1.46 \\
-0.09 \\
0.03 \\
-0.61\end{array}$ & $\begin{array}{l}0.39 \\
0.94 \\
0.83 \\
1.02 \\
0.79 \\
0.09 \\
0.63\end{array}$ \\
\hline \multicolumn{11}{|l|}{ Metabolic and biosynthetic processes } \\
\hline$\overline{\text { long-chain-fatty-acid-CoA ligase }}$ & -5.28 & -0.68 & 1.28 & 5.88 & -5.41 & 0.47 & -6.56 & 0.13 & 0.60 & -1.15 \\
\hline aldo/keto reductase & -2.87 & -0.39 & -0.05 & 2.43 & -2.96 & -0.54 & -2.82 & 0.09 & -0.44 & 0.15 \\
\hline fructose-bisphosphate aldolase 6 & -1.47 & -0.19 & 0.19 & 1.47 & -1.65 & -0.18 & -1.66 & 0.18 & 0.00 & -0.01 \\
\hline glutathione S-transferase & -1.34 & 0.17 & -0.24 & 1.27 & -1.60 & -0.33 & -1.10 & 0.26 & -0.07 & 0.50 \\
\hline methylglutaconyl-CoA hydratase & -1.12 & -0.21 & -0.14 & 0.77 & -1.38 & -0.61 & -0.98 & 0.26 & -0.34 & 0.40 \\
\hline oligosaccharyltransferase complex & -1.33 & 0.39 & -0.12 & 1.59 & -1.01 & 0.58 & -1.20 & -0.32 & 0.27 & -0.19 \\
\hline putative glyoxalase I & -2.13 & -0.47 & -0.48 & 1.18 & -1.56 & -0.38 & -1.65 & -0.57 & -0.95 & -0.09 \\
\hline UDP-glucose 4-epimerase & -1.15 & -0.59 & 0.08 & 0.64 & -0.89 & -0.25 & -1.23 & -0.26 & -0.51 & -0.34 \\
\hline asparagine synthetase & -0.69 & 0.29 & -0.31 & 0.67 & -1.42 & -0.75 & -0.38 & 0.73 & -0.02 & 1.05 \\
\hline isocitrate dehydrogenase [NADP] & 0.08 & -0.65 & 0.72 & -0.02 & 0.39 & 0.37 & -0.64 & -0.31 & 0.06 & -1.02 \\
\hline cytochrome b-c1 complex subu. Rieske & -0.08 & -1.57 & 0.95 & -0.54 & 0.81 & 0.27 & -1.03 & -0.89 & -0.62 & -1.84 \\
\hline cytochrome $\mathrm{c}$ oxidase subunit $5 \mathrm{~b}-1$ & -0.17 & -1.25 & 0.43 & -0.65 & 0.57 & -0.08 & -0.60 & -0.74 & -0.82 & -1.17 \\
\hline 2-oxoglutarate dehydrogenase & 0.17 & -1.08 & 0.35 & -0.90 & 0.70 & -0.20 & -0.18 & -0.53 & -0.73 & -0.88 \\
\hline adenylyl-sulfate kinase & 0.16 & -0.75 & -0.34 & -1.26 & 0.72 & -0.53 & 0.51 & -0.56 & -1.09 & -0.22 \\
\hline NADH dehydrogenase flavoprotein 1 & 0.89 & -0.80 & 0.72 & -0.97 & 1.09 & 0.12 & 0.17 & -0.20 & -0.08 & -0.92 \\
\hline phytanoyl-CoA dioxygenase & 1.12 & -0.40 & -0.10 & -1.61 & 1.37 & -0.24 & 1.22 & -0.25 & -0.49 & -0.15 \\
\hline fatty acyl-CoA synthetase & 0.97 & -0.34 & -0.23 & -1.55 & 1.57 & 0.02 & 1.20 & -0.60 & -0.58 & -0.37 \\
\hline UDP-glucose 4-epimerase GalE & 2.33 & -0.99 & 2.50 & -0.82 & 0.62 & -0.20 & -0.17 & 1.71 & 1.51 & -0.79 \\
\hline
\end{tabular}

Proton transmembrane transport, cell redox homeostasis and cellular detoxification

\begin{tabular}{llllllllllll}
\hline peroxiredoxin-1 & -1.28 & 0.57 & -0.73 & $\mathbf{1 . 1 3}$ & -0.40 & 0.73 & -0.56 & -0.88 & -0.15 & -0.15 \\
\hline
\end{tabular}


Table 4. Cont.

\begin{tabular}{|c|c|c|c|c|c|c|c|c|c|c|}
\hline \multirow[b]{2}{*}{ Protein Description } & \multicolumn{10}{|c|}{$\log _{2}$ (Fold-Change) } \\
\hline & $\begin{array}{l}\text { M31/ } \\
\text { M28 }\end{array}$ & $\begin{array}{l}\text { H31/ } \\
\text { H28 }\end{array}$ & $\begin{array}{l}\text { H28/ } \\
\text { M28 }\end{array}$ & $\begin{array}{l}\text { H31/ } \\
\text { M31 }\end{array}$ & $\begin{array}{c}\text { M31/ } \\
\text { C31 }\end{array}$ & $\begin{array}{c}\text { H31/ } \\
\text { C31 }\end{array}$ & $\begin{array}{c}\text { M31/ } \\
\text { H28 }\end{array}$ & $\begin{array}{l}\text { C31/ } \\
\text { M28 }\end{array}$ & $\begin{array}{l}\text { H31/ } \\
\text { M28 }\end{array}$ & $\begin{array}{l}\text { C31/ } \\
\text { H28 }\end{array}$ \\
\hline \multicolumn{11}{|l|}{ Protein folding, phosphorylation and transport } \\
\hline phage shock protein A homolog & -1.65 & 0.64 & -0.48 & 1.82 & -1.44 & 0.37 & -1.17 & -0.21 & 0.16 & 0.27 \\
\hline synaptobrevin domain-containing prot. & -0.09 & 0.89 & -0.78 & 0.20 & -0.62 & -0.42 & 0.69 & 0.54 & 0.12 & 1.31 \\
\hline CAMK/CDPK protein kinase & -0.07 & -0.13 & -1.20 & -1.27 & 0.51 & -0.76 & 1.13 & -0.58 & -1.33 & 0.62 \\
\hline sorting nexin 1 & 1.19 & -0.49 & 0.05 & -1.63 & 0.88 & -0.75 & 1.14 & 0.32 & -0.44 & 0.26 \\
\hline chaperone protein & 1.51 & 0.29 & 0.24 & -0.98 & 1.46 & 0.49 & 1.27 & 0.04 & 0.53 & -0.19 \\
\hline mitochondrial carrier family & -0.24 & -1.94 & 1.53 & -0.18 & -0.08 & -0.25 & -1.76 & -0.16 & -0.42 & -1.69 \\
\hline \multicolumn{11}{|l|}{ Proteolysis and autophagy } \\
\hline oligopeptidase B & -2.93 & -2.72 & 0.02 & 0.23 & -1.85 & -1.62 & -2.95 & -1.08 & -2.70 & -1.10 \\
\hline ubiquitin carboxyl-terminal hydrolase & -0.42 & -0.41 & 0.77 & 0.77 & -0.80 & -0.02 & -1.19 & 0.38 & 0.35 & -0.39 \\
\hline mitochondrial-processir & 0.00 & -0.81 & 0.79 & -0.02 & 0.38 & 0.36 & -0.79 & -0.39 & -0.03 & -1.18 \\
\hline mitochondrial-p & 0.22 & -0.92 & 0.75 & -0.40 & 0.69 & 0.29 & -0.53 & -0.47 & -0.18 & -1.22 \\
\hline ydrolase & 0.66 & -0.50 & -0.17 & -1.32 & 0.68 & -0.65 & 0.83 & -0.02 & -0.66 & 0.15 \\
\hline protein & 0.50 & -1.43 & 0.27 & -1.65 & 0.97 & -0.68 & 0.23 & -0.47 & -1.16 & -0.74 \\
\hline auto & 1.01 & 0.32 & -0.21 & -0.90 & 1.34 & 0.44 & 1.22 & -0.33 & 0.11 & -0.12 \\
\hline COP9 signalosome complex subun & -0.52 & -0.53 & -1.26 & -1.28 & 0.40 & -0.87 & 0.74 & -0.92 & -1.80 & 0.34 \\
\hline \multicolumn{11}{|l|}{ Translation and related process } \\
\hline amolnotain $\mathrm{C} P \mathrm{O}$ & -1.57 & -1.73 & 0.00 & -0.17 & -0.69 & -0.86 & -1.56 & -0.88 & -1.74 & -0.88 \\
\hline 605 ribos & -1.07 & -0.95 & 0.30 & 0.42 & -0.46 & -0.04 & -1.37 & -0.61 & -0.65 & -0.91 \\
\hline 605 ribos & -0.64 & -0.47 & 0.40 & 0.56 & -0.33 & 0.23 & -1.04 & -0.30 & -0.07 & -0.71 \\
\hline 605 acidic ribosom & 0.07 & -1.34 & 0.70 & -0.70 & 0.48 & -0.22 & -0.64 & -0.41 & -0.63 & -1.12 \\
\hline ribonuclease $\mathrm{P}$ prot & -0.28 & -0.93 & -0.25 & -0.90 & 0.75 & -0.15 & -0.03 & -1.03 & -1.18 & -0.78 \\
\hline ribonucleoside-diphosphate reductase & 0.59 & -2.64 & 2.08 & -1.15 & 0.76 & -0.39 & -1.49 & -0.17 & -0.56 & -2.24 \\
\hline $60 S$ ribosomal protein L5 & 0.98 & -1.93 & 0.52 & -2.38 & 1.23 & -1.15 & 0.45 & -0.25 & -1.40 & -0.78 \\
\hline & 1.01 & -1.33 & -0.13 & -2.46 & 1.78 & -0.68 & 1.13 & -0.77 & -1.46 & -0.65 \\
\hline ATP-dependent RNA helicase ddx6 & 2.86 & -0.74 & 0.15 & -3.44 & 1.48 & -1.96 & 2.70 & 1.37 & -0.58 & 1.22 \\
\hline \multicolumn{11}{|l|}{ Cytoskeleton and microtubule-based processes } \\
\hline tubulin alpha-3 chain & -0.02 & -0.76 & 0.72 & -0.02 & 0.28 & 0.26 & -0.74 & -0.30 & -0.04 & -1.02 \\
\hline villin-2 & 1.25 & 0.41 & -0.57 & -1.41 & 1.08 & -0.33 & 1.82 & 0.17 & -0.15 & 0.74 \\
\hline dynein $\mathrm{l}$ & 1.50 & 0.39 & -0.28 & -1.38 & 1.66 & 0.28 & 1.77 & -0.16 & 0.12 & 0.12 \\
\hline in-like & 0.48 & -1.01 & -0.52 & -2.02 & 1.36 & -0.66 & 1.01 & -0.88 & -1.53 & -0.35 \\
\hline dynein intermediate chain & 4.61 & -3.84 & 4.99 & -3.46 & 4.11 & 0.65 & -0.38 & 0.50 & 1.15 & -4.49 \\
\hline \multicolumn{11}{|l|}{ Unknown functions } \\
\hline$\overline{\text { tartrate-resistant acid phosphatase ty. } 5}$ & -2.28 & -1.51 & 1.19 & 1.95 & -2.80 & -0.85 & -3.47 & 0.52 & -0.33 & -0.66 \\
\hline hypothetical protein & -1.08 & 0.40 & -0.11 & 1.37 & -1.53 & -0.16 & -0.97 & 0.45 & 0.29 & 0.56 \\
\hline hypothetical protein & -1.62 & -0.57 & -0.03 & 1.02 & -1.51 & -0.49 & -1.59 & -0.11 & -0.60 & -0.08 \\
\hline hypothetical protein RFI_01644, partial & -0.32 & 0.62 & 0.13 & 1.07 & -0.91 & 0.16 & -0.45 & 0.59 & 0.75 & 0.46 \\
\hline hypothetical protein & -0.92 & 0.56 & -0.36 & 1.12 & -0.88 & 0.24 & -0.56 & -0.05 & 0.19 & 0.31 \\
\hline RING zinc finger-con & 0.83 & -0.46 & -0.14 & -1.43 & 1.19 & -0.24 & 0.97 & -0.36 & -0.60 & -0.22 \\
\hline hypothetical protein RFI_36204, partial & -3.22 & -0.89 & -2.23 & 0.10 & 0.16 & 0.26 & -0.99 & -3.38 & -3.12 & -1.15 \\
\hline
\end{tabular}

\section{Discussion}

LBF are important $\mathrm{CaCO}_{3}$ producers and ecological indicators integral to tropical marine habitats [19]. Increasing global $\mathrm{CO}_{2}$ emissions lead to simultaneous ocean acidification and warming, representing two major environmental threats to calcifying marine organisms. Understanding thresholds of physiological tolerance and possible acclimatization mechanisms to changing physicochemical conditions will help to better understand resilience mechanisms and the potential for persistence of coral reef organisms under near-future climate change. The geologic record of LBF throughout periods with high and strongly fluctuating atmospheric $p \mathrm{CO}_{2}$ and temperatures [24,25] has spurred interest in the abilities of photosymbiont-bearing foraminifera to withstand or adapt to rapidly changing ocean conditions. In our experiment, A. lobifera persists under the combined stressors of 
elevated $p \mathrm{CO}_{2}$ and $\mathrm{T}$ over an eight-week interval, showing only few effects induced by single stressor treatments or their interaction at the organism-level, but significant effects of temperature or $p \mathrm{CO}_{2}$ on the host and photosymbiont proteome.

\subsection{Climate Change Impacts on Photosymbiont and Holobiont Performance}

\subsubsection{Bleaching and Mortality}

Consistent with some previous studies on A. lobifera [12,43], we did not see significant impacts of elevated temperature or $p \mathrm{CO}_{2}$ (or their combined effects) on photosymbiont physiology as expressed by holobiont color and chl $a$ (Figure 2). While ocean warming is currently considered the most harmful factor of climate change on coral reef organisms, our study documented a resistance to $31^{\circ} \mathrm{C}$ and elevated $\mathrm{pCO}_{2}$. Importantly, we did not observe any significant effects on A. lobifera mortality in response to either of these global stressors, nor to their combined effects (Figure 3c). However, similar studies have shown that elevated $p \mathrm{CO}_{2}$, in combination with high temperatures [21,41] or elevated copper concentrations [46], induces bleaching and lowered chl $a$ concentration in other species of LBF. This suggests a species-specific and perhaps a study-specific response to significant interactions between multiple stressors on symbiont physiology. While elevated temperature alone has been documented to disrupt photosymbiosis as evidenced by reductions in photosymbiont density, pigment density, rate of photosynthesis, or coloration $[23,32,35,90]$, it is important to note the thermal history of specimens used in other studies likely differed from that of the present study-in which LBF were collected from a site previously shown to harbor highly thermally resistant populations of LBF and scleractinian corals $[22,37]$. Ultimately, the present study is consistent with previous experiments demonstrating no or low mortality in various LBF species exposed to OA $[41,46,47,91]$.

The proteomic response of the photosymbiont compartment offers interesting mechanistic insights into responses to $\mathrm{OW} / \mathrm{OA}$, showing these were primarily driven by elevated $\mathrm{T}$ and only secondarily by elevated $p \mathrm{CO}_{2}$. At $31^{\circ} \mathrm{C}$, particularly at moderate $p \mathrm{CO}_{2} \times 31^{\circ} \mathrm{C}$, proteins involved in photosynthesis (e.g., fucoxanthin chlorophyll $a / c$ protein, thylakoid lumenal $15 \mathrm{kDa}$ protein 2, PSI P700 apoproteins), several enzymes involved in (carbohydrate) metabolic processes (e.g., fructose-bisphosphate aldolase, alanine dehydrogenase, inorganic pyrophosphate), and various biosynthetic processes (e.g., uroporphyrinogen decarboxylase, 3-isoproylmalate dehydrogenase) were decreased. In contrast, proteins associated with unfolded protein response (e.g., HSP90, HSP70-type, ATP-dependent chaperone $\mathrm{ClpB}$ ) were elevated at $31{ }^{\circ} \mathrm{C}$ (Figures 5, 6a, S3, S5 and S6). Thus, we document here a similar but less intense proteomic symbiont stress response to OW compared to former studies on A. gibbosa [49]. Concurrently, the only changes observed between $p \mathrm{CO}_{2}$ treatments at $28{ }^{\circ} \mathrm{C}$ in diatom-associated proteins included slightly elevated chaperones, which are responsible for protein folding and repair, signifying a minor response of the photosymbionts to $p \mathrm{CO}_{2}$ levels approaching $3000 \mathrm{ppm}$ (Tables 3 and S6). Minimal gene expression responses to OA were correspondingly found for the in hospite photosymbiotic dinoflagellates of corals [92,93], which suggest that host-derived tissue may act as a buffer, or lower susceptibility of endosymbiotic microalgae to OA. This is also in line with the significantly lower proportion of DAPs in the photosymbionts compared to the host found here amongst $A$. lobifera from the GoA. As responses suggesting cellular stress or acclimatization mechanisms are only detectable at the proteome level, and not reflected in bleaching or mortality data, our results confirm the comparably high stability of the photosymbiosis of $A$. lobifera originating from the GoA [22], and emphasize corresponding proteomic responses to ocean warming to lessen the physiological impact of ocean warming and acidification conditions expected for years 2100 and 2500 (RCP 8.5 [1]). The high resilience of $A$. lobifera is further evident from an exposure experiment showing that seven species of LBF (including three Amphistegina species) surviving a five-day incubation at temperatures up to $40{ }^{\circ} \mathrm{C}$ and at $\mathrm{pH}$ between 5.9 and 7.4 [21]. 


\subsubsection{Growth}

While the LBF in our study did not exhibit significant mortality and bleaching, mean growth rates (2D planar extension) were generally lower under $31^{\circ} \mathrm{C}$ than under $28^{\circ} \mathrm{C}$ (Figure 3). Such reduced growth is consistent with prior temperature-stress studies on LBF (e.g., $[23,32,35,41])$. This is confirmed by the significant decrease in host protein abundances at $31^{\circ} \mathrm{C}$ (Figures 5, 6b and S4-S6) in the present study. This caused a depletion of mitochondrial components (e.g., metabolic enzymes involved in the tricarboxylic acid cycle) and components of the electron transport chain (e.g., putative glyoxalase I, UDPglucose 4-epimerase, isocitrate dehydrogenase [NADP], cytochrome c oxidase 1), but also of ribosomal and others proteins involved in translation (e.g., 60S and 40S ribosomal proteins, ribonuclease $\mathrm{P}$ protein subunit p25-like). Downregulation of reactive oxygen species (ROS)-producing reactions is a common proteomic response to reduce oxidative stress in marine organisms exposed to heat stress [94], while pathways that generate NADPH as a reducing equivalent for scavenging ROS may increase. This also emphasizes a potential decrease in energy production, which may affect resource allocation to the host or other cellular processes. Moreover, proteasome regulatory components (e.g., $26 \mathrm{~S}$ proteasome nonATPase regulatory subunit 1 homologue) decreased at $31^{\circ} \mathrm{C}$, while proteasome subunits responsible for protein catabolic processes increased (Tables 4 and S6). Simultaneously, increases in abundance were detected for a few proteins involved in protein transport and folding, or stress response (e.g., endoplasmin, chaperone proteins), and various proteins responsible for signal transduction, which may partly play roles in exocytosis, phagocytosis, or programmed cell death (Rab GTPase, Ras-related C3 botulinum toxin substrate 1, Ras-related protein RABB1c). All of these functional groups are likewise major traits of differential gene expression in the heat and bleaching responses of corals [95]. Hence, the dominant decreases in proteins from the $31^{\circ} \mathrm{C}$ treatments suggest cellular damage, reductions in energy production and cell-cycle related processes, and mild enhancement of unfolded protein response and repair processes.

The result of these proteomic changes suggests that fewer energy resources were available as a result of being reallocated to stress response mechanisms, potentially compromising growth. In comparison, one-month exposure of $A$. gibbosa to thermal stress $\left(32^{\circ} \mathrm{C}\right)$ likewise lead to reduced growth, but also to putative inhibition of reproduction, and to visible bleaching along with impacts on photophysiological parameters [23]. Accordingly, the proteomic response of $A$. gibbosa was more prominent, e.g., by stronger increased abundance of protein-folding and stress-related proteins [49]. These disparities indicate a higher resistance of $A$. lobifera to $\mathrm{OW}$, which may be related to the differing photosymbiont responses. While $A$. gibbosa hosts only one lineage of photosymbiotic diatoms [35], $A$. lobifera in contrast hosts a much higher diversity of photosymbionts [22,52], such that the higher flexibility in the photosymbiotic association may facilitate increased overall resilience of the holobiont. This is supported by the proteomic data, which show that despite reductions in photosynthesis-related, metabolic, and biosynthetic proteins in the photosymbiont, overall bleaching and mortality was not induced by elevated temperature.

An effect of elevated $p \mathrm{CO}_{2}$ alone on LBF growth was not found in the present study, which is similar to growth results of the closely related LBF species $A$. gibbosa that was not impacted by $p \mathrm{CO}_{2}$ of up to $2000 \mathrm{ppm}$ [43], suggesting that energetic reserves are relatively stable under OA conditions. Conversely, Prazeres et al. [47] detected significantly reduced buoyant weight growth rates in A. lessonii in response to seawater $\mathrm{pH}$ levels of 7.7 and lower, while no significant impacts on growth rates expressed by changes in surface area were found for the same individuals. Fujita et al. [40] likewise found heavier tests at intermediate $p \mathrm{CO}_{2}$ (580 and $\left.770 \mu \mathrm{atm}\right)$, but lower test weight at $970 \mu \mathrm{atm}$ in two other hyaline diatom-bearing foraminifera species. Recent work on the impacts of OA on coral calcification have documented a reduction in skeleton density, but not linear extension, in response to increasing $p \mathrm{CO}_{2}$ [96]. In our study, although not statistically significant, the lowest growth rates were found in the high- $p \mathrm{CO}_{2} \times 31^{\circ} \mathrm{C}$ treatment (Figure 3a). A marginally significant increase in the frequency of partial breakage was also observed 
in this treatment (Figure 3d), which may have arisen from underlying changes in test structure and density associated with the reduced growth rates under these conditions. Future studies into the effects of ocean acidification on LBF should therefore use methods that assess changes in test density, weight, and calcification rate.

Another impact of $\mathrm{OA}$ documented in the present study is a significant decrease in test pore size under high- $p \mathrm{CO}_{2} \times 31^{\circ} \mathrm{C}$ compared to control- $p \mathrm{CO}_{2} \times 31{ }^{\circ} \mathrm{C}$ (Figure $3 \mathrm{~b}$ ), which suggests that the structure of LBF tests may change under elevated $p \mathrm{CO}_{2}$, at least when combined with thermal stress. Such reduction in LBF pore size could limit the gas exchange between the environment and the $\mathrm{LBF}^{\prime}$ s inner cell. $\mathrm{A}{ }^{14} \mathrm{CO}_{2}$-experiment demonstrated that the pores of amphisteginids allow the exchange of photosynthesis- and respirationrelated gases, but not larger molecules [97]. Leutenegger and Hansen [97] also showed very slow $\mathrm{CO}_{2}$-uptake in $A$. lobifera compared to other species, and suggested that the organic pore elements may influence transport rates. Hence, the foraminiferal endoplasm and intercellular photosymbionts may confer some degree of protection from acidified environmental conditions.

\subsection{Buffering of $O A$ in the LBF Microenvironment}

Contrary to the majority of results documenting strong negative responses to $\mathrm{CO}_{2}-$ induced OA, such as dissolution of biogenic $\mathrm{CaCO}_{3}[98,99]$ and reducing overall fitness [43], the present study showed a generally mild response of LBF to OA. This is further documented through SEM images of test surfaces from living A. lobifera in treatments, which show no obvious signs of dissolution (Figure 4). Some prior studies on the response of amphisteginid and other LBF tests to environmental stress [21,40,43] suggest that the foraminiferal organic matrix, its ectoplasm, and/or reticulopodial network help protect the test from dissolution [100]. These processes are likely assisted by increasing $\mathrm{pH}-$ as observed in the present study-and, thus, calcite saturation state of the DBL around LBF tests.

Our study notably shows that $\mathrm{pH}$ at the test surface $\left(\mathrm{pH}_{\mathrm{ts}}\right)$ during dark is similar to surrounding seawater $\mathrm{pH}\left(\mathrm{pH}_{\mathrm{SW}}\right)$, while under light conditions $\mathrm{pH}_{\mathrm{ts}}$ at the LBF surface is elevated relative to $\mathrm{pH}_{\mathrm{SW}}$ (Figure $1 \mathrm{~b}$ ) - apparently due to the drawdown of DIC via symbiont photosynthesis under light conditions. Because DIC is a limiting substrate for photosynthesis in LBF [101], elevated $p \mathrm{CO}_{2}$ could therefore raise the photosynthetic output of the photosymbionts. Light-induced photosynthetic drawdown of DIC [67], as well as $\mathrm{CO}_{2}$-uptake for fixation in the Calvin cycle in the dark, outweighing respired $\mathrm{CO}_{2}$ [12] and/or active regulation of $\mathrm{CO}_{2}$ in the foraminiferal microenvironment have been previously proposed for LBF $[13,102]$, all of which would effectively minimize test dissolution by elevating $\mathrm{pH}_{\mathrm{ts}}$. Under light, the difference in proton concentration between seawater and test surface $\left(\Delta\left[\mathrm{H}^{+}\right]\right)$became significantly larger at high- $p \mathrm{CO}_{2} \times 31^{\circ} \mathrm{C}$ (Figure 1a), such that the resulting $\mathrm{pH}_{\mathrm{ts}}(7.84 \pm 0.21)$ was approaching $\mathrm{pH}_{\mathrm{ts}}$ at moderate- $p \mathrm{CO}_{2} \times 31^{\circ} \mathrm{C}$ $(7.96 \pm 0.04)$. Such elevated $\mathrm{pH}$ at the LBFs' test surface under light was similarly observed in A radiata at 1141 and $2151 \mu \mathrm{atm}$ [12], potentially indicating a shielding effect of maintaining a strong proton gradient in the DBL due to enhanced photosynthetic uptake of aqueous $\mathrm{CO}_{2}$ under conditions of elevated $p \mathrm{CO}_{2}$. Ecologically, photosynthesis and DBL thickness of LBF depend on flow rates [67], which they can control to some degree through their own motility, potentially allowing them to control DBL thickness and its protective function.

The mechanisms primarily considered responsible for the observed persistence of calcification in LBF under $\mathrm{OA}$ are active elevation of $\mathrm{pH}$ at the site of calcification via proton pumping (e.g., by V-type $\mathrm{H}^{+}$-ATPase, $\mathrm{Ca}^{2+}$-ATPase and $\mathrm{Mg}$-ATPase $[47,103]$ ) and/or antiporter exchange, and/or drawdown of aqueous $\mathrm{CO}_{2}$ via photosynthesis [67], which compensate for the $\mathrm{CO}_{2}$-induced decrease in seawater $\mathrm{pH}$ and maintain $\mathrm{pH}$ homeostasis for cellular function [104]. Yet, proton gradients $\left(\Delta\left[\mathrm{H}^{+}\right]\right)$in the LBF microenvironment weakened significantly under dark conditions (Figure 1a), with $\mathrm{pH}$ at the test surface becoming nearly indistinguishable from seawater $\mathrm{pH}$ ) under all treatments (Figure 1b) - 
suggesting that light is essential for maintaining the chemically protective $\mathrm{pH}$ gradients in the DBL of this species.

Notably, the A. lobifera maintained a much higher $\mathrm{pH}_{\mathrm{ts}}$ and stronger $\Delta\left[\mathrm{H}^{+}\right]$in the highest $p \mathrm{CO}_{2}$ treatment under $31^{\circ} \mathrm{C}$ compared with $28^{\circ} \mathrm{C}$, suggesting that this species is able to mitigate the impacts of extreme OA under the higher temperature treatment. This trend is not borne out in the growth data (as measured by change in cross-sectional area of test), which under the highest $p \mathrm{CO}_{2}$ treatment showed higher growth under $28^{\circ} \mathrm{C}$ versus $31^{\circ} \mathrm{C}$. Interestingly, members of several electron transport complexes (e.g., cytochrome b-c1 complex subunit Rieske, cytochrome c oxidase subunit 5b-1, NADHubiquinone oxidoreductase, NADH dehydrogenase [ubiquinone] flavoprotein 1) increased with elevated $p \mathrm{CO}_{2}$, particularly at high- $p \mathrm{CO}_{2} \times 28^{\circ} \mathrm{C}(\mathrm{H} 28)$, but not at $31^{\circ} \mathrm{C}$ (Figures S4-S6, Table 4 and Table S6), suggesting that these may contribute to cellular homeostasis of this species under $\mathrm{OA}$ in the absence of thermal stress, but that these processes are not reflected in DBL chemistry.

Although the PERMANOVA indicated significant effects of $p \mathrm{CO}_{2}$ on global protein abundances in both compartments, the generally low number of DAPs and lack of proteomic data showing consistent regulation of common proton pumps (i.e., V-type proton ATPase subunits and vacuolar membrane proton pumps) under the elevated $p \mathrm{CO}_{2}$ treatments suggest that host cellular $\mathrm{pH}$ homeostasis was maintained without substantial regulatory response. Only a slight increase of these in control- and high- $p \mathrm{CO}_{2} \times 31{ }^{\circ} \mathrm{C}$ hint at active regulation of $\mathrm{CO}_{2}$ in the $\mathrm{LBFs}^{\prime}$ microenvironment. In contrast, direct comparison of proteomic responses to high- and moderate- $p \mathrm{CO}_{2} \times 28^{\circ} \mathrm{C}$ (Table 4 and Table S6) suggests slightly reduced ion transport and protein phosphorylation (pyrophosphate-energized vacuolar membrane proton pump 1-like, V-type proton ATPase subunits, CAMK/CDPK protein kinase) under high compared to moderate $p \mathrm{CO}_{2}$. The few increased host-proteins under high $p \mathrm{CO}_{2}$ were involved in carbohydrate metabolic processes and proteolysis (e.g., UDP-glucose 4-epimerase GalE, proteasome subunit alpha type-4-3). Similarly, a surprising lack of changes in abundance of ATP-driven proton pumps or even lower levels of proton pumps were evident in similarly designed coral OA experiments $[105,106]$. Nevertheless, though not statistically significant, $\Delta \mathrm{H}^{+}$was also apparently enhanced at high- $p \mathrm{CO}_{2} \times 31^{\circ} \mathrm{C}$ in the dark (Figure 1a), suggesting that other mechanisms facilitating proton regulation in the DBL may have been at work. These mechanisms could include higher activity of known ion pumps, or enhancement of so far unrecognized proton-regulating mechanisms and/or proteins.

\subsection{Non-Linear Responses to Multiple Climate Change Stressors}

The overall fitness in A. lobifera was largely unaffected by the climate change scenarios to which they were exposed in the present study. However, contrasting responses to the interaction of OA and OW were identified. Previous studies have highlighted taxonspecific and non-linear responses $([8,11])$ to OA, which were observed in the present study in the high amounts of DAPs, indicating cellular acclimatization mechanisms that facilitate the physiological functions of LBF, in response to moderate- $p \mathrm{CO}_{2} \times 31^{\circ} \mathrm{C}$, but not to high- $p \mathrm{CO}_{2} \times 31^{\circ} \mathrm{C}$.

The proteomic response to moderate- $p \mathrm{CO}_{2} \times 31^{\circ} \mathrm{C}$ is clearly anomalous in intensity and direction of variation (Figures $5 \mathrm{c}$ and 6 ), although this treatment did not cause detectable differences in other aspects of LBF physiology. The abundances of most DAPs decreased in the moderate- $p \mathrm{CO}_{2} \times 31^{\circ} \mathrm{C}$ treatment, with only a small proportion increasing. The decreased proteins are involved in light harvesting, metabolic processes and protontransmembrane transport (e.g., fucoxanthin chlorophyll $a / c$ proteins, divinyl chlorophyllide a 8-vinyl-reductase, thylakoid luminal $15 \mathrm{kDa}$ protein 2), lipid trafficking (translocation protein sec 62), or cytoplasm organization (tubulin-specific chaperone, cell division protein FtsZ), biosynthetic processes and cell redox homeostasis (e.g., uroporphyrinogen decarboxylase, thioredoxin). Proteins involved in chlorophyll biosynthesis (e.g., geranylgeranyl reductase) increased, probably to offset the decrease in light-harvesting antenna proteins. 
Simultaneously, other proteins involved in biosynthetic and metabolic processes or cell redox homeostasis (e.g., aspartate-ammonia ligase, $40 \mathrm{~S}$ ribosomal protein, dihydrolipoyl dehydrogenase), and protein folding and degradation (e.g., Clp-protease ATP binding subunit, ATP-dependent chaperone $\mathrm{ClpB}$ ) increased. Overall, this hints at a stress-induced response of the photosymbionts under the moderate- $p \mathrm{CO}_{2} \times 31{ }^{\circ} \mathrm{C}$ treatment, probably related to oxidative stress. Although not detectable in chl $a$ (Figure 2a), the photophysiological condition of the symbionts may have been compromised. Hence, despite a presumably fertilizing effect of elevated DIC availability on photosynthesis, the $\Delta \mathrm{H}^{+}$under light in this treatment stayed at the same level as under the control- $p \mathrm{CO}_{2} \times 31^{\circ} \mathrm{C}$ treatment (Figure 1). Thus, the proteomic response observed at moderate- $p \mathrm{CO}_{2} \times 31^{\circ} \mathrm{C}$ was probably caused by oxidative and cell-redox stress offsetting the benefit of increased DIC available for symbiont photosynthesis under the year-2100 scenario.

Such cellular responses in the photosymbionts may affect holobiont performance by reducing transfer of resources. In the host proteome, in contrast, various proteins were enriched, and respiratory activity was highest in this treatment, as indicated by the lowered $\mathrm{pH}_{\mathrm{ts}}$ in the dark. Some proteins involved in fatty-acid oxidation and mitochondrial electron transport (e.g., fatty-acid CoA synthase, phytanoyl-CoA dioxygenase) were increased, while other enzymes involved in fatty-acid and glucose metabolism (e.g., long-chainfatty-acid-CoA ligase, fructose-bisphosphate aldolase) were depleted. Altered fatty-acid metabolism was previously identified as part of the core transcriptomic response of corals to OA [107]. The downregulation of fatty-acid catabolism and simultaneous upregulation of a fatty-acid synthesis indicate increased lipid storage, possibly a common acclimatization mechanism of photosymbiotic calcifiers to long-term acidification. However, several other metabolic proteins decreased, along with cell cycle-related processes (e.g., cullin-associated NEDD8-dissociated protein 1, eukaryotic initiation factor 4E), and signal transduction and regulation (e.g., GTPase HRas, Ras-related protein Rab-21), while proteins involved in translational, protein folding and degradation (e.g., 605 ribosomal protein L5, molecular chaperone Dank/HSP70, peroxiredoxin, autophagy-related protein 3), cytoskeleton or microtubule movement (dynein intermediate and heavy chain, clathrin light chain, villin2), and protein phosphorylation or transport (e.g., putative vesicle-fusing ATPase, sorting nexin 1), increased. These processes likely reflect an oxidative stress response, including repair mechanisms and cytoskeleton restructuring, as observed previously $[49,85]$.

LBF from the high- $p \mathrm{CO}_{2} \times 31^{\circ} \mathrm{C}$ treatment exhibited an unexpectedly low number of DAPs and showed high similarity to LBF from the control- $p \mathrm{CO}_{2} \times 31^{\circ} \mathrm{C}$ treatment (Figures 5, 6 and S2-S4, Table S7). Yet, $\mathrm{pH}_{\mathrm{ts}}$ was significantly elevated to $\sim 7.84$ in the light (Figure 1) under high- $p \mathrm{CO}_{2} \times 31^{\circ} \mathrm{C}$. This indicates enhanced photosynthesis at $\sim$ high$p \mathrm{CO}_{2} \times 31^{\circ} \mathrm{C}$, although no significant change in chl $a$, color, or photosynthesis-related proteins were detected (Figure 2, Tables 3 and S6). Thus, higher chloroplast efficiency under elevated $p \mathrm{CO}_{2}$ possibly enhanced photosynthetic productivity [12] without further proteomic adjustments. Decreases of a few proteins related to biosynthetic processes, oxidative stress, and cell redox homeostasis (e.g., acetyl-coA carboxylase, taurine catabolism dioxygenase TauD, glutamate synthase 2, L-ascorbate peroxidase,) and increases of DAPs, related to protein folding and proton transport (e.g., T-complex protein 1 subunit eta, V-type proton ATPase proteolipid subunit), imply minor cellular effects that could indicate an acclimative mechanism that can potentially maintain cell redox homeostasis. This mild response underscores the high fitness of photosymbionts in the high- $p \mathrm{CO}_{2} \times 31^{\circ} \mathrm{C}$ treatment, potentially facilitated by the fertilizing effect of OA on diatoms [8] and enhanced enzyme activities at high $\mathrm{T}$. This further means the response of LBF photosymbionts to OA is non-linear when combined with warming. Hence, the impacts of $31^{\circ} \mathrm{C}$ and putative cell redox stress observed in moderate- $p \mathrm{CO}_{2} \times 31^{\circ} \mathrm{C}$ are neutralized by the fertilizing effects of elevated $p \mathrm{CO}_{2}$ at a threshold between $\sim 1000$ and $3000 \mathrm{ppm}$. This seems to contradict the observation that DIC uptake of $A$. lobifera is close to saturation at ambient $p \mathrm{CO}_{2}$ [101], as higher temperatures facilitate higher enzymatic activities, which were presumably a limiting factor for $\mathrm{CO}_{2}$-fixation via symbiont photosynthesis in previous studies. 
In the host proteome, only a very minor response was detectable at high- $p \mathrm{CO}_{2} \times 31^{\circ} \mathrm{C}$, therefore, no major proteomic responses were required, probably due to fully functional photosymbionts and/or the chemical protection conferred from the strong proton gradient maintained in their DBL, or limitations in gas exchange through reductions in pore size. This underscores how well-adjusted these prolific calcifiers are to low $\mathrm{pH}$ environments, as long as the activity of their photosymbionts is unaffected.

\section{Conclusions}

Climate change will have diverse and complex ecological consequences for marine ecosystems. Overall, the effects of two-months exposure to $31{ }^{\circ} \mathrm{C}$ elicited a more adverse response than exposure to $\mathrm{CO}_{2}$-induced acidification at $p \mathrm{CO}_{2}$ conditions up to $\sim 3000$ ppm, which indicates the relatively high tolerance of A. lobifera to OA, potentially a result of a conserved adaptive trait in this and many other photosymbiotic Red Sea species $[22,37,38,108,109]$. However, both elevated $p \mathrm{CO}_{2}$ and temperature, but not their interaction, had significant effects on foraminifera and diatom proteomes. The frequency of these differentially abundant proteins was significantly higher in the foraminifera, indicating a stronger proteomic response in the host compared to its endosymbiotic diatoms. A mild heat-stress response was shown by the predominant decrease in protein abundances and reduced holobiont growth, indicating reduced holobiont performance through chronic sublethal cellular stress. OA showed even fewer effects on LBF. All $p \mathrm{CO}_{2}$ scenarios appear to be within the adaptive range of $A$. lobifera from the GoA. This sets their $\mathrm{CO}_{2}$ threshold above those previously proposed for Amphistegina spp. (e.g., for Great Barrier Reef populations: $1141 \mu \mathrm{atm} p \mathrm{CO}_{2} / \mathrm{pH}_{\mathrm{NBS}} 7.85$ [12]) and other hyaline foraminifera (e.g., from the northwest Pacific $1000 \mu \mathrm{atm} / \mathrm{pH}_{\mathrm{SW}} 7.7$ [40]). Yet at $31^{\circ} \mathrm{C}$, elevated $p \mathrm{CO}_{2}$ induced cellular and morphological alterations (e.g., strongest proteome variations at moderate$p \mathrm{CO}_{2}$ [year-2100]), indicating non-linear responses to combined stressors, and adaptive mechanism. Microenvironmental proton gradients $\left[\Delta \mathrm{H}^{+}\right]$increasing with elevated $p \mathrm{CO}_{2}$ and light denote the organism's ability to mitigate the acidified conditions, especially during photosynthetic activity of the endosymbiotic diatoms. These responses may come at energetic costs that ultimately limit the host's resistance to climate change, as previous studies suggest $[40,47]$, resulting in the reduced test growth and marginally increased frequency in test breakage under higher- $p \mathrm{CO}_{2}$ conditions observed in the present study. In general, the effects of OA (and its combination with other stressors) on LBF are highly variable amongst species and studies [19], possibly owing to differences in test structure (hyaline vs. porcellaneous), mineral polymorph solubility (aragonite vs. low-Mg calcite vs. high-Mg calcite [110]), calcification mechanism [111], environmental preconditioning, compounding environmental factors (e.g., light, flow, nutrient availability, pesticides), life stage, flexibility in feeding strategies, and/or photosymbiont community.

Ancestral Amphisteginidae and other hyaline LBF, such as nummulitids, were diverse and dominant in shallow tropical marine carbonate environments during the middle Eocene [24,25], when atmospheric $\mathrm{CO}_{2}$ levels were similar to or markedly higher than today and underwent strong fluctuations [26,112]. The survival and, in some cases, proliferation of foraminifera throughout this interval invited the hypothesis that LBF possess important adaptations to changing $\mathrm{pCO}_{2}$. The ability of Amphistegina to continue calcifying under a wide range of $p \mathrm{CO}_{2}$ conditions, as observed in the present study, may have allowed this family of LBF to thrive during the middle Eocene and may facilitate their persistence in the future. The relative tolerance of these LBF to near-future climate change suggests a growing dominance in inter-reef and reef flat foraminifera assemblages [57] and further range expansions [22,113], along with a potential increased importance as carbonate producers. It also confirms the low susceptibility of coral reef organisms from the Gulf of Aqaba [22,37], which suggests that the northern Red Sea is a potentially important marine refuge from climate change [114], requiring strengthened protection and study.

The presented exploration of LBF holobiont response to the combined and singular effects of $\mathrm{OA}$ and $\mathrm{OW}$ at the level of the proteome yields valuable information about 
cellular stress responses, and the potential for physiological plasticity and resilience in the face of global climate change. Whether the putative acclimatization mechanisms can uphold overall fitness over longer time scales, and at what costs (e.g., energetic costs and/or physiological tradeoffs), should be assessed in future studies. With regard to the lack of signs of stress in the evaluated physiological parameters, but apparent proteomic responses, this study highlights the importance of considering impacts at several functional levels of the organism, as sublethal effects that can be (temporarily) overcome by acclimatization mechanisms at the molecular level, may not be detectable otherwise. Our experiment also shows that the effects of climate change can be missed when related stressors are assessed in isolation, and that physiological responses should be assessed across a range of organismal levels in order to make more realistic projections about the fate of reef calcifiers.

Supplementary Materials: The following are available online at https:/ /www.mdpi.com/article/10 .3390/oceans2020017/s1, Figure S1: Phylogenetic assignment of photosymbionts; Figure S2: Heatmap of differentially abundant proteins per sample; Figure S3: Heatmap of differentially abundant proteins in photosymbionts; Figure S4: Heatmap of differentially abundant proteins of the host foraminifera; Figure S5: Principal component analysis of differentially abundant proteins in (a) photosymbionts and (b) foraminiferal host including GO term summaries; Figure S6: Principal component analysis of differentially abundant proteins in (a) photosymbionts and (b) foraminiferal host including protein descriptions; Figure S7: Number of up- and down-regulated proteins comparing all treatments; Figure S8: Bar plots showing the number of gene ontology term hits of (a) $p \mathrm{CO}_{2}$ - and (b) temperature-regulated proteins; Table S1: Additional data for mean chemical conditions; Table S2: Results of nominal logistic models for the frequencies of test breakage and mortality; Table S3: PERMANOVA and pairwise comparison results for $\Delta\left[\mathrm{H}^{+}\right]$; Table S4: Results of two-factorial ANOVA of the measured physiological parameters; Table S5: List of all proteins detected; Table S6: List of normalized abundances values and $\log _{2}$ FC of all DAPs; Table S7: Number of DAPs observed in experimental treatments.

Author Contributions: Conceptualization, M.S., J.B.R., and C.E.R.; methodology, M.S., L.P.C., C.E.R. and B.B.-L.; sample collection, M.S., C.E.R.; experimental setup, J.B.R., L.P.C.; proteomics analysis, B.B.-L.; data analysis, M.S.; writing-original draft preparation, M.S.; writing-review and editing, C.E.R., S.S.D., L.P.C., B.B.-L., J.B.R., H.W.; visualization, M.S.; supervision, J.B.R., H.W., A.S.; funding acquisition, J.B.R., H.W., A.S. All authors have read and agreed to the published version of the manuscript.

Funding: This project was supported by a Hanse Wissenschaftskolleg (HWK) senior fellowship and NSF BIO-OCE grant (funding number 1437371) awarded to J.B.R., and a grant from the Leibniz Association (funding number SAW-ISAS-2014) awarded to A.S. and H.W. Further, the Leibniz Centre for Tropical Marine Research (ZMT), and the Leibniz Institut für Analytische Wissenschaften (ISAS) contributed to the funding. M.S. was supported by the Minerva Foundation.

Data Availability Statement: The data presented in this study are openly available in PANGAEA at https:/ / doi.pangaea.de/10.1594/PANGAEA.904656, diatom sequences were deposited at European Nucleotide Archive (ENA) under the project accession number PRJEB33832, and proteomic data in the ProteomeXchange Consortium via the PRIDE partner repository under dataset identifier PXD009890.

Acknowledgments: We warmly acknowledge Amatzia Genin and the Interuniversity Institute of Marine Science (IUI) for supporting sampling at the IUI, as well as Christian Wöhle and AlexandraSophie Roy for providing their protein prediction data set. We thank Silvia Hardenberg, Nico Steinel, and Christian Brandt for their assistance with the aquarium facilities at ZMT, and Achim Meyer for support with symbiont sequencing. We thank Dirk de Beer and the technicians from the Microsensor Group, especially Anja Niclas, at the Max-Planck Institute for Marine Microbiology.

Conflicts of Interest: The authors declare no conflict of interest. The funders had no role in the design of the study; in the collection, analyses, or interpretation of data; in the writing of the manuscript, or in the decision to publish the results. 


\section{Appendix A}

Proteomics Analysis

The following chemicals were obtained from Sigma Aldrich, Steinheim, Germany: anhydrous magnesium chloride $\left(\mathrm{MgCl}_{2}\right)$, guanidine hydrochloride $(\mathrm{GuHCl})$, iodoacetamide (IAA), ammonium bicarbonate $\left(\mathrm{NH}_{4} \mathrm{HCO}_{3}\right)$, and urea. Sodium chloride $(\mathrm{NaCl})$ and calcium chloride $\left(\mathrm{CaCl}_{2}\right)$ were from Merck, Darmstadt. Sodium dodecyl sulfate (SDS) was bought from Carl Roth, Karlsruhe, Germany. Tris base was purchased from Applichem Biochemica, Darmstadt, Germany. Dithiothreitol (DTT), EDTA-free protease inhibitor (Complete Mini) tablets were obtained from Roche Diagnostics, Mannheim, Germany. Sequencing grade-modified trypsin was bought from Promega, Madison, WI USA. All chemicals for ultra-pure HPLC solvents such as formic acid (FA), trifluoroacetic acid (TFA), and acetonitrile (ACN) were obtained from Biosolve, Valkenswaard, the Netherlands.

Lysis of pooled specimens was performed in $1.5 \mathrm{~mL}$ Eppendorf tubes. $100 \mu \mathrm{L}$ of lysis buffer (50 mM Tris-HCl, pH 7.8, $150 \mathrm{mM} \mathrm{NaCl}, 1 \%$ SDS, and Complete Mini) were added, followed by mechanical grinding and storage on ice for $30 \mathrm{~min}$. For clarification, samples were centrifuged at $4{ }^{\circ} \mathrm{C}$ and $10000 \mathrm{rcf}$ for $10 \mathrm{~min}$.

Protein concentration was estimated based on reference samples of which the exact protein concentration was determined by amino acid analysis as previously described $[115,116]$. Reduction and alkylation was performed by addition of DTT to a final concentration of $10 \mathrm{mM}$ and incubation at $56^{\circ} \mathrm{C}$ for $30 \mathrm{~min}$, followed by treatment with $30 \mathrm{mM}$ IAA at room temperature in the dark.

A filter aided sample preparation workflow (FASP) $[117,118]$ with slight changes was used for buffer exchange and proteolysis. Lysates corresponding to an approximated protein concentration of $8 \mu \mathrm{g}$ were diluted 5-fold by addition of freshly prepared $8.0 \mathrm{M}$ Urea/100 mM Tris- $\mathrm{HCl}$ ( $\mathrm{pH}$ 8.5) [119] and transferred onto the centrifugal device (PALL Nanosep, $30 \mathrm{kDa}$ cutoff). After an initial centrifugation step for $30 \mathrm{~min}$ at $13500 \mathrm{rcf}$ at RT, all following centrifugation steps were performed for $15 \mathrm{~min}$, keeping the other parameters constant. Three wash steps with $100 \mu \mathrm{L}$ of $8.0 \mathrm{M}$ Urea/100 mM Tris- $\mathrm{HCl}(\mathrm{pH} 8.5)$ were followed by three steps of buffer exchange with $100 \mu \mathrm{L}$ of $50 \mathrm{mM} \mathrm{NH}_{4} \mathrm{HCO}_{3}(\mathrm{pH}$ 7.8). $100 \mu \mathrm{L}$ of proteolysis buffer comprising trypsin (1:20 w/w ratio of enzyme to substrate), $0.2 \mathrm{M} \mathrm{GuHCl}$, and $2 \mathrm{mM} \mathrm{CaCl}_{2}$ in $50 \mathrm{mM} \mathrm{NH}_{4} \mathrm{HCO}_{3}$ (pH 7.8) was added to each sample. After incubation at $37^{\circ} \mathrm{C}$ for $14 \mathrm{~h}$, digested peptides were recovered by centrifugation followed by consecutive washing steps with $50 \mu \mathrm{L}$ of $50 \mathrm{mM} \mathrm{NH}_{4} \mathrm{HCO}_{3}$ and $50 \mu \mathrm{L}$ of ultrapure water. Samples were acidified by addition of $20 \mu \mathrm{L}$ of $10 \%$ TFA, desalted using SPEC $\mathrm{C} 18,4 \mathrm{mg}$ sorbent (Agilent) as per manufacturer's instructions, and quality controlled as described previously [120].

A TIC based normalization was performed by measurement of aliquots of all samples on a nano LC-MS system to account for systematic errors. Samples (each $1 \mu \mathrm{g}$ after normalization) were analyzed using an Ultimate 3000 nano RSLC system coupled to a Q Exactive HF mass spectrometer (both Thermo Scientific). Preconcentration on a $100 \mu \mathrm{m}$ $\times 2 \mathrm{~cm} \mathrm{C18} \mathrm{trapping} \mathrm{column} \mathrm{for} 10$ min using $0.1 \%$ TFA with a flow rate of $20 \mu \mathrm{L} \mathrm{min}{ }^{-1}$ was followed by separation on a $75 \mu \mathrm{m} \times 50 \mathrm{~cm}$ C18 main column (both PepMap RSLC, Thermo Scientific) with a 120 min LC gradient ranging from 3-35\% of buffer B: $84 \%$ ACN,

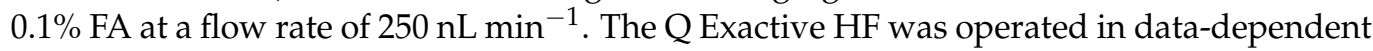
acquisition mode and MS survey scans were acquired from m/z 300 to 1500 at a resolution of 60,000 using the polysiloxane ion at m/z 371.101236 as lock mass [121]. Quadrupole isolation was set to $0.4 \mathrm{~m} / \mathrm{z}$ and the fifteen most intense signals (Top15) were subjected to higher energy collisional dissociation with a normalized collision energy of $27 \%$ at a resolution of 15,000 and a dynamic exclusion of $12 \mathrm{~s}$. Automated gain control target values were set to $3 \times 106$ for MS and $5 \times 104$ MS/MS. Maximum injection times were $120 \mathrm{~ms}$ and $250 \mathrm{~ms}$, respectively. Precursor ions with charge states of $+1,>+5$ or unassigned were excluded from MS/MS analysis.

Progenesis LC-MS software (version 3.0.6039.34628) from Nonlinear Dynamics (Newcastle upon Tyne, UK) and the statistical software R (version 3.3.162) [84] were used for 
label-free quantification. Raw MS data was imported into Progenesis and aligned to one automatically selected LC-MS reference file. After peak picking, MS/MS spectra were exported .mgf files. Identification of proteins and peptides was performed by the PEAKS Studio software suite, version 7.5, de novo to SPIDER [122]. Searches were performed in a decoy-fusion manner against a concatenated database comprising an updated and enlarged reference dataset for foraminifera, containing the recently published genome sequences of the calcareous benthic foraminifera Globobulimina [81], combined with the publicly available genome data of three diatom species (Bacillariophyta) from the NCBI database on 15 March 2016. Protein sequence databases were used as such, while nucleotide sequences were translated in all six reading frames prior to concatenation. Precursor mass tolerance was set to $10 \mathrm{ppm}$ and fragment ion tolerance to $0.02 \mathrm{Da}$. Full tryptic enzyme specificity was selected, allowing a maximum of two missed cleavages. For de novo and DB search, carbamidomethylation of cysteines was defined as fixed modification and oxidation of methionine as variable modification. A maximum number of two variable modifications per peptide was allowed for de novo and DB search, while for the PTM and SPIDER search the default settings were used. PSM- and peptide-level FDR was limited to $1 \%$ and proteins had to be identified with at least one unique peptide in order to be reported. Identifications meeting these criteria were re-imported into Progenesis to calculate the normalized abundances on the peptide-level.

Amino acid sequences of all proteins identified in the database search were uploaded in .fasta file format to the CD-HIT suite web server of the Weizhong Li Lab [123] in order to generate cluster of homologous protein sequences. Sequence identity cut-off was set to 0.7 and minimum alignment coverage for the longer sequence was set to 0.0. All other parameters were left as default. Normalized abundance-values of the peptides were used to calculate protein cluster abundance. Only peptides unique to a given protein cluster were used for quantification, hence, peptides that could not be clearly assigned to either of the compartments (host or symbionts) were removed from further analysis.

\section{References}

1. Field, C.B.; Barros, V.R. (Eds.) Climate Change 2014-Impacts, Adaptation and Vulnerability: Regional Aspects; Cambridge University Press: Cambridge, UK; New York, NY, USA, 2014.

2. Hughes, T.P.; Kerry, J.T.; Álvarez-Noriega, M.; Álvarez-Romero, J.G.; Anderson, K.D.; Baird, A.H.; Babcock, R.C.; Beger, M.; Bellwood, D.R.; Berkelmans, R.; et al. Global warming and recurrent mass bleaching of corals. Nature 2017, 543, $373-377$. [CrossRef]

3. Caldeira, K.; Wickett, M.E. Anthropogenic carbon and ocean pH. Nature 2003, 425, 365. [CrossRef]

4. Feely, R.A.; Alin, S.R.; Newton, J.; Sabine, C.L.; Warner, M.; Devol, A.; Krembs, C.; Maloy, C. The combined effects of ocean acidification, mixing, and respiration on $\mathrm{pH}$ and carbonate saturation in an urbanized estuary. Estuar. Coast. Shelf Sci. 2010, 88, 442-449. [CrossRef]

5. Orr, J.C.; Fabry, V.J.; Aumont, O.; Bopp, L.; Doney, S.C.; Feely, R.A.; Gnanadesikan, A.; Gruber, N.; Ishida, A.; Joos, F.; et al. Anthropogenic ocean acidification over the twenty-first century and its impact on calcifying organisms. Nature 2005, $437,681$. [CrossRef]

6. Pandolfi, J.M.; Connolly, S.R.; Marshall, D.J.; Cohen, A.L. Projecting coral reef futures under global warming and ocean acidification. Science 2011, 333, 418-422. [CrossRef]

7. Ries, J.B. A physicochemical framework for interpreting the biological calcification response to $\mathrm{CO}_{2}$-induced ocean acidification. Geochim. Cosmochim. Acta 2011, 75, 4053-4064. [CrossRef]

8. Kroeker, K.J.; Kordas, R.L.; Crim, R.; Hendriks, I.E.; Ramajo, L.; Singh, G.S.; Duarte, C.M.; Gattuso, J.P. Impacts of ocean acidification on marine organisms: Quantifying sensitivities and interaction with warming. Glob. Chang. Biol. 2013, 19, 1884-1896. [CrossRef] [PubMed]

9. Castillo, K.D.; Ries, J.B.; Bruno, J.F.; Westfield, I.T. The reef-building coral Siderastrea siderea exhibits parabolic responses to ocean acidification and warming. Proc. R. Soc. B Biol. Sci. 2014, 281. [CrossRef]

10. Ries, J.B.; Cohen, A.L.; McCorkle, D.C. Marine calcifiers exhibit mixed responses to $\mathrm{CO}_{2}$-induced ocean acidification. Geology 2009, 37, 1131-1134. [CrossRef]

11. Ries, J.B.; Cohen, A.L.; McCorkle, D.C. A nonlinear calcification response to $\mathrm{CO}_{2}$-induced ocean acidification by the coral Oculina arbuscula. Coral Reefs 2010, 29, 661-674. [CrossRef]

12. Glas, M.S.; Fabricius, K.E.; de Beer, D.; Uthicke, $\mathrm{S}$. The $\mathrm{O}_{2}, \mathrm{pH}$ and $\mathrm{Ca}^{2+}$ microenvironment of benthic foraminifera in a high $\mathrm{CO}_{2}$ world. PLoS ONE 2012, 7, e50010. [CrossRef] 
13. De Nooijer, L.J.; Toyofuku, T.; Kitazato, H. Foraminifera promote calcification by elevating their intracellular pH. PNAS 2009, 106, 15374-15378. [CrossRef]

14. Toyofuku, T.; Matsuo, M.Y.; de Nooijer, L.J.; Nagai, Y.; Kawada, S.; Fujita, K.; Reichart, G.-J.; Nomaki, H.; Tsuchiya, M.; Sakaguchi, H.; et al. Proton pumping accompanies calcification in foraminifera. Nat. Commun. 2017, 8, 14145. [CrossRef]

15. Guillermic, M.; Cameron, L.; De Corte, I.; Misra, S.; Bijma, J.; De Beer, D.; Reymond, C.; Westphal, H.; Ries, J.B.; Eagle, R. Thermal stress reduces Pocilloporid coral resilience to ocean acidification by impairing control over calcifying fluid chemistry. Sci. Adv. 2021, 7, eaba9958. [CrossRef]

16. Hallock, P. Symbiont-bearing foraminifera: Harbingers of global change? Micropaleontology 2000, 46, 95-104.

17. Lee, J.J.; Saks, N.M.; Kapiotou, F.; Wilen, S.H.; Shilo, M. Effects of host cell extracts on cultures of endosymbiotic diatoms from larger foraminifera. Mar. Biol. 1984, 82, 113-120. [CrossRef]

18. Langer, M.R. Assessing the contribution of foraminiferan protists to global ocean carbonate production. J. Eukaryot. Microbiol. 2008, 55, 163-169. [CrossRef] [PubMed]

19. Narayan, G.R.; Reymond, C.E.; Stuhr, M.; Doo, S.; Schmidt, C.; Mann, T.; Westphal, H. Response of large benthic foraminifera to climate and local changes: Implications for future carbonate production. Sedimentology 2021. [CrossRef]

20. Hallock, P. Why are larger Foraminifera large? Paleobiology 1985, 11, 195-208. [CrossRef]

21. Engel, B.E.; Hallock, P.; Price, R.E.; Pichler, T. Shell dissolution in larger benthic foraminifers exposed to $\mathrm{pH}$ and temperature extremes: Results from an in situ experiment. J. Foraminifer. Res. 2015, 45, 190-203. [CrossRef]

22. Schmidt, C.; Morard, R.; Prazeres, M.; Barak, H.; Kucera, M. Retention of high thermal tolerance in the invasive foraminifera Amphistegina lobifera from the Eastern Mediterranean and the Gulf of Aqaba. Mar. Biol. 2016, 163, 228. [CrossRef]

23. Stuhr, M.; Reymond, C.E.; Rieder, V.; Hallock, P.; Westphal, H.; Kucera, M. Reef calcifiers are adapted to episodic heat stress but vulnerable to sustained warming. PLoS ONE 2017, 12, e0179753. [CrossRef]

24. Pomar, L.; Baceta, J.I.; Hallock, P.; Mateu-Vicens, G.; Basso, D. Reef building and carbonate production modes in the west-central Tethys during the Cenozoic. Mar. Pet. Geol. 2017, 83, 261-304. [CrossRef]

25. Hallock, P.; Silva, I.P.; Boersma, A. Similarities between planktonic and larger foraminiferal evolutionary trends through Paleogene paleoceanographic changes. Palaeogeogr. Palaeoclimatol. Palaeoecol. 1991, 83, 49-64. [CrossRef]

26. Pearson, P.; Palmer, M. Middle eocene seawater $\mathrm{pH}$ and atmospheric carbon dioxide concentrations. Science 1999, $284,1824-1826$. [CrossRef] [PubMed]

27. Prazeres, M.; Morard, R.; Roberts, T.E.; Doo, S.; Schmidt, C.; Stuhr, M.; Renema, W.; Kucera, M. High dispersal capacity and biogeographic breaks shape the genetic diversity of a globally-distributed reef-dwelling calcifier. Ecol. Evol. 2020, 10, 5976-5989. [CrossRef]

28. Langer, M.R.; Hottinger, L. Biogeography of selected "larger" foraminifera. Micropaleontology 2000, 46, 105-126.

29. Langer, M.R.; Weinmann, A.E.; Lötters, S.; Bernhard, J.M.; Rödder, D. Climate-driven range extension of Amphistegina (Protista, Foraminiferida): Models of current and predicted future ranges. PLoS ONE 2013, 8, e54443. [CrossRef]

30. Doo, S.S.; Hamylton, S.; Finfer, J.; Byrne, M. Spatial and temporal variation in reef-scale carbonate storage of large benthic foraminifera: A case study on One Tree Reef. Coral Reefs 2016, 36, 293-303. [CrossRef]

31. Kawahata, H.; Fujita, K.; Iguchi, A.; Inoue, M.; Iwasaki, S.; Kuroyanagi, A.; Maeda, A.; Manaka, T.; Moriya, K.; Takagi, H.; et al. Perspective on the response of marine calcifiers to global warming and ocean acidification-Behavior of corals and foraminifera in a high $\mathrm{CO}_{2}$ world "hot house". Prog. Earth Planet. Sci. 2019, 6, 37. [CrossRef]

32. Schmidt, C.; Heinz, P.; Kucera, M.; Uthicke, S. Temperature-induced stress leads to bleaching in larger benthic foraminifera hosting endosymbiotic diatoms. Limnol. Oceanogr. 2011, 56, 1587-1602. [CrossRef]

33. Talge, H.K.; Hallock, P. Ultrastructural responses in field-bleached and experimentally stressed Amphistegina gibbosa (Class Foraminifera). J. Eukaryot. Microbiol. 2003, 50, 324-333. [CrossRef] [PubMed]

34. Fujita, K.; Okai, T.; Hosono, T. Oxygen metabolic responses of three species of large benthic foraminifers with algal symbionts to temperature stress. PLoS ONE 2014, 9, e90304. [CrossRef] [PubMed]

35. Stuhr, M.; Meyer, A.; Reymond, C.E.; Narayan, G.R.; Rieder, V.; Rahnenführer, J.; Kucera, M.; Westphal, H.; Muhando, C.A.; Hallock, P. Variable thermal stress tolerance of the reef-associated symbiont-bearing foraminifera Amphistegina linked to differences in symbiont type. Coral Reefs 2018, 37, 811-824. [CrossRef]

36. Hallock, P.; Williams, D.; Toler, S.; Fisher, E.M.; Talge, H.K. Bleaching in reef-dwelling foraminifers: Implications for reef decline. Int. Coral Reef Symp. 2006, 737, 729-737.

37. Fine, M.; Gildor, H.; Genin, A. A coral reef refuge in the Red Sea. Glob. Chang. Biol. 2013, 19, 3640-3647. [CrossRef]

38. Osman, E.O.; Smith, D.J.; Ziegler, M.; Kürten, B.; Conrad, C.; El-Haddad, K.M.; Voolstra, C.R.; Suggett, D.J. Thermal refugia against coral bleaching throughout the northern Red Sea. Glob. Chang. Biol. 2018, 24, 474-484. [CrossRef]

39. Uthicke, S.; Momigliano, P.; Fabricius, K.E. High risk of extinction of benthic foraminifera in this century due to ocean acidification. Sci. Rep. 2013, 3, 1769. [CrossRef]

40. Fujita, K.; Hikami, M.; Suzuki, A.; Kuroyanagi, A.; Kawahata, H. Effects of ocean acidification on calcification of symbiont-bearing reef foraminifera. Biogeosci. Discuss. 2011, 8, 1809-1829.

41. Schmidt, C.; Kucera, M.; Uthicke, S. Combined effects of warming and ocean acidification on coral reef foraminifera Marginopora vertebralis and Heterostegina depressa. Coral Reefs 2014, 33, 805-818. [CrossRef] 
42. Uthicke, S.; Fabricius, K.E. Productivity gains do not compensate for reduced calcification under near-future ocean acidification in the photosynthetic benthic foraminifer species Marginopora vertebralis. Glob. Chang. Biol. 2012, 18, 2781-2791. [CrossRef]

43. McIntyre-Wressnig, A.; Bernhard, J.M.; McCorkle, D.C.; Hallock, P. Non-lethal effects of ocean acidification on the symbiontbearing benthic foraminifer Amphistegina gibbosa. Mar. Ecol. Prog. Ser. 2013, 472, 45-60. [CrossRef]

44. Reymond, C.E.; Lloyd, A.; Kline, D.I.; Dove, S.G.; Pandolfi, J.M. Decline in growth of foraminifer Marginopora rossi under eutrophication and ocean acidification scenarios. Glob. Chang. Biol. 2013, 19, 291-302. [CrossRef] [PubMed]

45. Vogel, N.; Uthicke, S. Calcification and photobiology in symbiont-bearing benthic foraminifera and responses to a high $\mathrm{CO}_{2}$ environment. J. Exp. Mar. Bio. Ecol. 2012, 424-425, 15-24. [CrossRef]

46. Marques, J.A.; de Barros Marangoni, L.F.; Bianchini, A. Combined effects of sea water acidification and copper exposure on the symbiont-bearing foraminifer Amphistegina gibbosa. Coral Reefs 2017, 36, 489-501. [CrossRef]

47. Prazeres, M.; Uthicke, S.; Pandolfi, J.M. Ocean acidification induces biochemical and morphological changes in the calcification process of large benthic foraminifera. Proc. R. Soc. B Biol. Sci. 2015, 282, 8-11. [CrossRef]

48. Sinutok, S.; Hill, R.; Doblin, M.; Wuhrer, R.; Ralph, P. Warmer more acidic conditions cause decreased productivity and calcification in subtropical coral reef sediment-dwelling calcifiers. Limnol. Oceanogr. 2011, 56, 1200-1212. [CrossRef]

49. Stuhr, M.; Blank-Landeshammer, B.; Reymond, C.E.; Kollipara, L.; Sickmann, A.; Kucera, M.; Westphal, H. Disentangling thermal stress responses in a reef-calcifier and its photosymbionts by shotgun proteomics. Sci. Rep. 2018, 8, 3524. [CrossRef]

50. Lee, J.J. Algal symbiosis in larger foraminifera. Symbiosis 2006, 42, 63-75.

51. Lee, J.J.; McEnery, M.E.; ter Kuile, B.; Erez, J.; Röttger, R.; Rockwell, R.F.; Faber, W., Jr.; Lagziel, A.; Faber, W., Jr.; Lagziel, A. Identification and distribution of endosymbiotic diatoms in larger foraminifera. Micropaleontology 1989, 35, 353-366. [CrossRef]

52. Prazeres, M.; Roberts, T.E.; Ramadhani, S.F.; Doo, S.S.; Schmidt, C.; Stuhr, M.; Renema, W. Diversity and flexibility of algal symbiont community in globally distributed larger benthic foraminifera of the genus Amphistegina. BMC Microbiol. 2021. in review.

53. Hallock, P. Production of carbonate sediments by selected large benthic foraminifera on two Pacific coral reefs. J. Sediment. Petrol. 1981, 51, 467-474.

54. ter Kuile, B.; Erez, J. In situ growth rate experiments on the symbiont-bearing foraminifera Amphistegina lobifera and Amphisorus hemprechii. J. Foraminifer. Res. 1984, 14, 262-276. [CrossRef]

55. Segev, E.; Erez, J. Effect of Mg/Ca ratio in seawater on shell composition in shallow benthic foraminifera. Geochem. Geophys. Geosyst. 2006, 7, Q02P09. [CrossRef]

56. Hallock, P. Distribution of selected species of living algal symbiont-bearing foraminifera on two Pacific coral reefs. J. Foraminifer. Res. 1984, 14, 250-261. [CrossRef]

57. Renema, W. Terrestrial influence as a key driver of spatial variability in large benthic foraminiferal assemblage composition in the Central Indo-Pacific. Earth Sci. Rev. 2018, 177, 514-544. [CrossRef]

58. Hallock, P.; Forward, L.B.; Hansen, H.J. Influence of environment on the test shape of Amphistegina. J. Foraminifer. Res. 1986, 16, 224-231. [CrossRef]

59. Hansen, H.J.; Buchard, B. Depth distribution of Amphistegina in the Gulf of Elat, Israel. In Depth-Relationships of Recent Larger Foraminifera in the Gulf of Aqaba-Elat; Reiss, Z., Leutenegger, S., Hottinger, L., Fermont, W.J.J., Meulenkamp, J.E., Thomas, E., Hansen, H.J., Buchardt, B., Larsen, A.R., Drooger, C.W., Eds.; Micropaleontological Bulletins: Utrecht, The Netherlands, 1977; pp. 205-224.

60. Cameron, L.P.; Reymond, C.E.; Bijma, J.; Büscher, J.V.; de Beer, D.; Eagle, R.T.; Gunnell, J.; Müller-Lundin, F.; Schmidt-Grieb, G.M.; Westfield, I.; et al. Impacts of warming and acidification on corals linked to symbiont abundance and pH-regulation. Preprints 2021. [CrossRef]

61. Lee, J.; Erez, J.; ter Kuile, B.; Lagziel, A.; Burgos, S. Feeding rates of two species of larger foraminifera Amphistegina lobifera and Amphisorus hemprichii, from the Gulf of Eilat (Red Sea). Symbiosis 1988, 5, 61-102.

62. Lee, J.J.; Sang, K.; ter Kuile, B.; Strauss, E.; Lee, P.J.; Faber, W.W. Nutritional and related experiments on laboratory maintenance of three species of symbiont-bearing, large foraminifera. Mar. Biol. 1991, 109, 417-425. [CrossRef]

63. Lewis, E.; Wallace, D. Program Developed for $\mathrm{CO}_{2}$ System Calculations; Environmental Sciences Division publication: Oak Ridge, TN, USA, 1998.

64. Roy, R.N.; Roy, L.N.; Vogel, K.M.; Portermoore, C.; Pearson, T.; Good, C.E.; Millero, F.J.; Campbell, D.M. The dissociation constants of carbonic acid in seawater at salinities 5 to 45 and temperatures 0 to $45^{\circ} \mathrm{C}$. Mar. Chem. 1993, 44, 249-267. [CrossRef]

65. Mucci, A. The solubility of calcite and aragonite in seawater at various salinities, temperatures and one atmosphere total pressure. Am. J. Sci. 1983, 283, 780-799. [CrossRef]

66. Cai, W.J.; Ma, Y.; Hopkinson, B.M.; Grottoli, A.G.; Warner, M.E.; Ding, Q.; Hu, X.; Yuan, X.; Schoepf, V.; Xu, H.; et al. Microelectrode characterization of coral daytime interior $\mathrm{pH}$ and carbonate chemistry. Nat. Commun. 2016, 7, 1-8. [CrossRef] [PubMed]

67. Köhler-Rink, S.; Kühl, M. Microsensor studies of photosynthesis and respiration in larger symbiotic foraminifera. I The physicochemical microenvironment of Marginopora vertebralis, Amphistegina lobifera and Amphisorus hemprichii. Mar. Biol. 2000, 137, 473-486. [CrossRef]

68. de Beer, D.; Schramm, A.; Santegoeds, C.M.; Kühl, M. A nitrite microsensor for profiling environmental biofilms. Appl. Environ. Microbiol. 1997, 63, 973-977. [CrossRef] [PubMed] 
69. Bernhard, J.M. Distinguishing live from dead foraminifera: Methods review and proper applications. Micropaleontology 2000, 46, 38-46.

70. Schindelin, J.; Arganda-Carreras, I.; Frise, E.; Kaynig, V.; Longair, M.; Pietzsch, T.; Preibisch, S.; Rueden, C.; Saalfeld, S.; Schmid, B.; et al. Fiji: An open-source platform for biological-image analysis. Nat. Methods 2012, 9, 676-682. [CrossRef]

71. Hosono, T.; Fujita, K.; Kayanne, H. Estimating photophysiological condition of endosymbiont-bearing Baculogypsina sphaerulata based on the holobiont color represented in CIE $L^{*} a^{*} b^{*}$ color space. Mar. Biol. 2012, 159, 2663-2673. [CrossRef]

72. Schwartzwald, D. Color Space Converter Plugin for Imagej. Available online: https://imagej.nih.gov/ij/plugins/color-spaceconverter.html (accessed on January 2017).

73. Petersen, J.; Riedel, B.; Barras, C.; Pays, O.; Guihéneuf, A.; Mabilleau, G.; Schweizer, M.; Meysman, F.J.R.; Jorissen, F.J. Improved methodology for measuring pore patterns in the benthic foraminiferal genus Ammonia. Mar. Micropaleontol. 2016, 128, 1-13. [CrossRef]

74. Benjamini, Y.; Hochberg, Y. Controlling the False Discovery Rate-A practical and powerful approach to multiple testing. J. R. Stat. Soc. Ser. B 1995, 57, 289-300. [CrossRef]

75. Zhang, Z.; Schwartz, S.; Wagner, L.; Miller, W. A greedy algorithm for aligning DNA sequences. J. Comput. Biol. 2000, 7, 203-214. [CrossRef]

76. Katoh, K.; Misawa, K.; Kuma, K.I.; Miyata, T. MAFFT: A novel method for rapid multiple sequence alignment based on fast Fourier transform. Nucleic Acids Res. 2002, 30, 3059-3066. [CrossRef] [PubMed]

77. Hall, T.A. BioEdit: A user friendly biological sequence alignment editor and analysis program for Windows 95/98/NT. Nucleic Acids Symp. Ser. 1999, 41, 95-98.

78. Glez-Peña, D.; Gómez-Blanco, D.; Reboiro-Jato, M.; Fdez-Riverola, F.; Posada, D. ALTER: Program-oriented conversion of DNA and protein alignments. Nucleic Acids Res. 2010, 38, 14-18. [CrossRef] [PubMed]

79. Tamura, K.; Stecher, G.; Peterson, D.; Filipski, A.; Kumar, S. MEGA6: Molecular Evolutionary Genetics Analysis. Mol. Biol. Evol. 2013, 30, 2725-2729. [CrossRef] [PubMed]

80. Vizcaíno, J.A.; Csordas, A.; Del-Toro, N.; Dianes, J.A.; Griss, J.; Lavidas, I.; Mayer, G.; Perez-Riverol, Y.; Reisinger, F.; Ternent, T.; et al. Update of the PRIDE database and its related tools. Nucleic Acids Res. 2016, 44, D447-D456. [CrossRef] [PubMed]

81. Woehle, C.; Roy, A.-S.; Glock, N.; Wein, T.; Weissenbach, J.; Rosenstiel, P.; Hiebenthal, C.; Michels, J.; Schönfeld, J.; Dagan, T. A novel eukaryotic denitrification pathway in foraminifera. Curr. Biol. 2018, 28, 2536-2543. [CrossRef]

82. Huerta-Cepas, J.; Szklarczyk, D.; Heller, D.; Hernández-Plaza, A.; Forslund, S.K.; Cook, H.; Mende, D.R.; Letunic, I.; Rattei, T.; Jensen, L.J.; et al. EggNOG 5.0: A hierarchical, functionally and phylogenetically annotated orthology resource based on 5090 organisms and 2502 viruses. Nucleic Acids Res. 2019, 47, 309-314. [CrossRef] [PubMed]

83. Huerta-Cepas, J.; Forslund, K.; Coelho, L.P.; Szklarczyk, D.; Jensen, L.J.; Von Mering, C.; Bork, P. Fast genome-wide functional annotation through orthology assignment by eggNOG-mapper. Mol. Biol. Evol. 2017, 34, 2115-2122. [CrossRef]

84. R Core Team. R: A Language and Environment for Statistical Computing; R Core Team: Vienna, Austria, 2016.

85. Oakley, C.A.; Durand, E.; Wilkinson, S.P.; Peng, L.; Weis, V.M.; Grossman, A.R.; Davy, S.K. Thermal shock induces host proteostasis disruption and endoplasmic reticulum stress in the model symbiotic cnidarian Aiptasia. J. Proteome Res. 2017, 16, 2121-2134. [CrossRef]

86. Sproles, A.E.; Oakley, C.A.; Matthews, J.L.; Peng, L.; Owen, J.G.; Grossman, A.R.; Weis, V.M.; Davy, S.K. Proteomics quantifies protein expression changes in a model cnidarian colonised by a thermally tolerant but suboptimal symbiont. ISME J. 2019, 13, 2334-2345. [CrossRef]

87. Oksanen, J.; Blanchet, F.G.; Kindt, R.; Legendre, P.; Minchin, P.R.; O’Hara, R.B.; Simpson, G.L.; Solymos, P.; Stevens, M.H.H.; Wagner, H. Vegan: Community Ecology Package. Available online: https://cran.r-project.org/web/packages/vegan (accessed on May 2020).

88. Hervé, M. Aide-Mémoire de Statistique Appliquée à la Biologie-Construire son Étude et Analyser les Résultats à L'aide du Logiciel R. Available online: https://cran.r-project.org/doc/contrib/Herve-Aide-memoire-statistique.pdf (accessed on January 2021).

89. Barnes, K.H. Diversity and distribution of diatom endosymbionts in Amphistegina spp. (Foraminifera) based on molecular and morphological techniques; University of South Florida: Tampa, FL, USA, 2016.

90. Doo, S.S.; Fujita, K.; Byrne, M.; Uthicke, S. Fate of calcifying tropical symbiont-bearing large benthic foraminifera: Living sands in a changing ocean. Biol. Bull. 2014, 226, 169-186. [CrossRef] [PubMed]

91. McIntyre-Wressnig, A.; Bernhard, J.M.; McCorkle, D.C.; Hallock, P. Non-lethal effects of ocean acidification on two symbiontbearing benthic foraminiferal species. Biogeosci. Discuss. 2011, 8, 9165-9200.

92. Davies, S.W.; Ries, J.B.; Marchetti, A.; Castillo, K.D. Symbiodinium functional diversity in the coral Siderastrea siderea is influenced by thermal stress and reef environment, but not ocean acidification. Front. Mar. Sci. 2018, 5, 150. [CrossRef]

93. González-Pech, R.A.; Vargas, S.; Francis, W.R.; Wörheide, G. Transcriptomic resilience of the Montipora digitata holobiont to Low pH. Front. Mar. Sci. 2017, 4, 403. [CrossRef]

94. Tomanek, L. Proteomic responses to environmentally induced oxidative stress. J. Exp. Biol. 2015, 218, 1867-1879. [CrossRef]

95. Cleves, P.A.; Shumaker, A.; Lee, J.M.; Putnam, H.M.; Bhattacharya, D. Unknown to known: Advancing knowledge of coral gene function. Trends Genet. 2020, 36, 93-104. [CrossRef] [PubMed] 
96. Mollica, N.R.; Guo, W.; Cohen, A.L.; Huang, K.F.; Foster, G.L.; Donald, H.K.; Solow, A.R. Ocean acidification affects coral growth by reducing skeletal density. Proc. Natl. Acad. Sci. USA 2018, 115, 1754-1759. [CrossRef] [PubMed]

97. Leutenegger, S.; Hansen, H.J. Ultrastructural and radiotracer studies of pore function in foraminifera. Mar. Biol. 1979, 54, 11-16. [CrossRef]

98. Kleypas, J.A.; Buddemeier, R.W.; Archer, D.; Gattuso, J.P.; Langdon, C.; Opdyke, B.N. Geochemical consequences of increased atmospheric carbon dioxide on coral reefs. Science 1999, 284, 118-120. [CrossRef]

99. Ries, J.B.; Ghazaleh, M.N.; Connolly, B.; Westfield, I.; Castillo, K.D. Impacts of seawater saturation state $(\Omega A=0.4-4.6)$ and temperature $\left(10,25^{\circ} \mathrm{C}\right)$ on the dissolution kinetics of whole-shell biogenic carbonates. Geochim. Cosmochim. Acta 2016, 192, 318-337. [CrossRef]

100. Travis, J.; Bowser, S. The motility of foraminifera. In Biology of Foraminifera; Academic Press: London, UK, $1991 ;$ pp. 91-155.

101. Ter Kuile, B.; Erez, J.; Padan, E. Mechanisms for the uptake of inorganic carbon by two species of symbiont-bearing foraminifera. Mar. Biol. 1989, 103, 241-251. [CrossRef]

102. Bentov, S.; Brownlee, C.; Erez, J. The role of seawater endocytosis in the biomineralization process in calcareous foraminifera. Proc. Natl. Acad. Sci. USA 2009, 106, 21500-21504. [CrossRef] [PubMed]

103. Erez, J. The source of ions for biomineralization in foraminifera and their implications for paleoceanographic proxies (Review). Rev. Miner. Geochem. 2003, 54, 115. [CrossRef]

104. Sutton, J.N.; Liu, Y.W.; Ries, J.B.; Guillermic, M.; Ponzevera, E.; Eagle, R.A. $\delta^{11} \mathrm{~B}$ as monitor of calcification site $\mathrm{pH}$ in divergent marine calcifying organisms. Biogeosciences 2018, 15, 1447-1467. [CrossRef]

105. Moya, A.; Huisman, L.; Ball, E.E.; Hayward, D.C.; Grasso, L.C.; Chua, C.M.; Woo, H.N.; Gattuso, J.P.; Forêt, S.; Miller, D.J. Whole transcriptome analysis of the coral Acropora millepora reveals complex responses to $\mathrm{CO}_{2}$-driven acidification during the initiation of calcification. Mol. Ecol. 2012, 21, 2440-2454. [CrossRef]

106. Rocker, M.M.; Noonan, S.; Humphrey, C.; Moya, A.; Willis, B.L.; Bay, L.K. Expression of calcification and metabolism-related genes in response to elevated $p \mathrm{CO}_{2}$ and temperature in the reef-building coral Acropora millepora. Mar. Genom. 2015, 24, 313-318. [CrossRef]

107. Kenkel, C.D.; Moya, A.; Strahl, J.; Humphrey, C.; Bay, L.K. Functional genomic analysis of corals from natural $\mathrm{CO}_{2}$-seeps reveals core molecular responses involved in acclimatization to ocean acidification. Glob. Chang. Biol. 2018, 24, 158-171. [CrossRef] [PubMed]

108. Bellworthy, J.; Fine, M. Beyond peak summer temperatures, branching corals in the Gulf of Aqaba are resilient to thermal stress but sensitive to high light. Coral Reefs 2017, 36, 1071-1082. [CrossRef]

109. Krueger, T.; Horwitz, N.; Bodin, J.; Giovani, M.-E.; Escrig, S.; Meibom, A.; Fine, M. Common reef-building coral in the northern Red Sea resistant to elevated temperature and acidification. R. Soc. Open Sci. 2017, 4, 170038. [CrossRef]

110. Ries, J.B. Skeletal mineralogy in a high-CO $\mathrm{CO}_{2}$ world. J. Exp. Mar. Bio. Ecol. 2011, 403, 54-64. [CrossRef]

111. Robbins, L.L.; Knorr, P.O.; Wynn, J.G.; Hallock, P.; Harries, P.J. Interpreting the role of pH on stable isotopes in large benthic foraminifera. ICES J. Mar. Sci. 2017, 74, 955-964. [CrossRef]

112. Purton, L.M.A.; Brasier, M.D. Giant protist Nummulites and its Eocene environment: Life span and habitat insights from $\delta^{18} \mathrm{O}$ and $\delta^{13} \mathrm{C}$ data from Nummulites and Venericardia, Hampshire basin, UK. Geology 1999, 27, 711-714. [CrossRef]

113. Weinmann, A.E.; Rödder, D.; Lötters, S.; Langer, M.R. Heading for new shores: Projecting marine distribution ranges of selected larger foraminifera. PLOS ONE 2013, 8, 14. [CrossRef]

114. Kleinhaus, K.; Al-Sawalmih, A.; Barshis, D.J.; Genin, A.; Grace, L.N.; Hoegh-Guldberg, O.; Loya, Y.; Meibom, A.; Osman, E.O.; Ruch, J.-D.; et al. Science, diplomacy, and the Red Sea's unique coral reef: It's time for action. Front. Mar. Sci. 2020, 7, 00090. [CrossRef]

115. Cohen, S.A.; Michaud, D.P. Synthesis of a fluorescent derivatizing reagent, 6-aminoquinolyl-N-hydroxysuccinimidyl carbamate, and its application for the analysis of hydrolysate amino acids via high-performance liquid chromatography. Anal. Biochem. 1993, 211, 279-287. [CrossRef] [PubMed]

116. Shindo, N.; Nojima, S.; Fujimura, T.; Taka, H.; Mineki, R.; Murayama, K. Separation of 18 6-aminoquinolyl-carbamyl-amino acids by ion-pair chromatography. Anal. Biochem. 1997, 249, 79-82. [CrossRef]

117. Manza, L.L.; Stamer, S.L.; Ham, A.-J.L.; Codreanu, S.G.; Liebler, D.C. Sample preparation and digestion for proteomic analyses using spin filters. Proteomics 2005, 5, 1742-1745. [CrossRef] [PubMed]

118. Wisniewski, J.R.; Zougman, A.; Nagaraj, N.; Mann, M. Universal sample preparation method for proteome analysis. Nat. Methods 2009, 6, 359-362. [CrossRef]

119. Kollipara, L.; Zahedi, R.P. Protein carbamylation: In vivo modification or in vitro artefact? Proteomics 2013, 13, 941-944. [CrossRef]

120. Burkhart, J.M.; Schumbrutzki, C.; Wortelkamp, S.; Sickmann, A.; Zahedi, R.P. Systematic and quantitative comparison of digest efficiency and specificity reveals the impact of trypsin quality on MS-based proteomics. J. Proteom. 2012, 75, 1454-1462. [CrossRef] [PubMed]

121. Olsen, J.V.; de Godoy, L.M.; Li, G.; Macek, B.; Mortensen, P.; Pesch, R.; Makarov, A.; Lange, O.; Horning, S.; Mann, M. Parts per million mass accuracy on an Orbitrap mass spectrometer via lock mass injection into a C-trap. Mol. Cell. Proteom. 2005, 4, 2010-2021. [CrossRef] [PubMed] 
122. Zhang, J.; Xin, L.; Shan, B.; Chen, W.; Xie, M.; Yuen, D.; Zhang, W.; Zhang, Z.; Lajoie, G.A.; Ma, B. PEAKS DB: De novo sequencing assisted database search for sensitive and accurate peptide identification. Mol. Cell. Proteom. 2012, 11, 010587. [CrossRef]

123. Huang, Y.; Niu, B.; Gao, Y.; Fu, L.; Li, W. CD-HIT Suite: A web server for clustering and comparing biological sequences. Bioinformatics 2010, 26, 680-682. [CrossRef] [PubMed] 